\title{
A new chromosomal locus associated with gut- modulated phenotypes in Salmonella enterica serotype Typhimurium
}

\author{
MARIANNE ROBEY, EIRWEN MORGAN, JULIA M. LODGE, ALEX J. BOLTON, \\ GILLIAN D. MARTIN, NIGEL L. BROWN and JOHN STEPHEN
}

Molecular Microbiology Group, School of Biosciences, University of Birmingham, Edgbaston, Birmingham B15 2TT

\begin{abstract}
A cosmid DNA library had been constructed previously from 40-kb fragments of genomic DNA from a virulent invasive strain of Salmonella enterica serotype Typhimurium (TML) in an avirulent hypo-invasive Typhimurium strain (LT7). Selection of invasive clones from the library was attempted by iterative passage through a rabbit ileal organ culture. After the fourth passage, a clone, designated LT7(pHC20.2), was isolated. Exposure to both gut tissue and Caco-2 cells enhanced the growth, invasiveness for gut and Caco-2 cells, and flagellin expression of LT7(pHC20.2) although its invasiveness was less than that of strain TML. Expression of appendages (surface structures $c$. 60-70 $\mathrm{nm}$ diameter) was shown to play a role in but not to confer invasiveness, and was demonstrated in the absence of direct contact with eukaryotic cells. Exposure to gut tissue also affected the expression of several outer-membrane proteins (OMPs) in all four Salmonella strains - TML, LT7, LT7(pHC79), LT7(pHC20.2) used in this work. As the genes involved in flagella, invasin and porin expression are distributed around the salmonella chromosome, it is possible that pHC20.2 encodes a pleiotropic regulator of genes involved in gastro-enteritic virulence and adaptation to the in-vivo gut environment. $\mathrm{pHC20} \cdot 2$ mapped at $c$. centisome 25 on the salmonella chromosome close to, but distinct from, SPI-5.
\end{abstract}

\section{Introduction}

In recent years, huge efforts have been invested in identifying the nature and organisation of molecular determinants responsible for various aspects of Salmonella-host interaction and the regulatory mechanisms involved in their expression. The discovery [1] of Salmonella invasion (inv) genes, whose products were responsible for penetration of tissue culture cells, together with the emergent concept of the pathogenicity island - a region of horizontally acquired DNA which confers virulence-associated features upon the host bacterium [2] - has led to major advances in this field. The inv genes are now known to be part of a complex Salmonella pathogenicity island (SPI1) [3]. At least five SPIs [3] have been identified, of which at least two (SPI1 and 5) are known to be involved in gastroenteritic rather than systemic infections caused by

Received 29 April 2001; revised version received 31 July 2001; accepted 2 Aug. 2001.

Corresponding author: Dr J. Stephen (e-mail: J.Stephen@ bham.ac.uk).
Salmonella enterica serotype Dublin in calves [4,5]. Furthermore, a bewildering plethora of environmental conditions and regulatory factors that control expression of virulence factors have been identified in various pathogens including Salmonella spp. [6] evoking the following perceptive comment. 'Although in-vitro studies can provide attractive models for in-vivo gene regulation, caution must be exercised when attempting to extrapolate relevant in-vivo signals from environmental cues that regulate virulence genes in vitro. There is little direct evidence to identify the conditions that bacteria encounter at different sites during infection, and signals that regulate virulence genes in vitro may not be the same as those modulating these genes in vivo. In some cases, in-vitro cues may operate by an artificial process that bypasses the in-vivo signalling mechanism' [6].

The detailed study of pathogenic mechanisms operative in Salmonella-induced human disease requires suitable models; only in the case of non-human host-adapted Salmonella serotypes is it possible to perform experiments on the pathogenesis of salmonella infection 
in the natural host, such as chickens, cattle and pigs [7-9]. The most relevant in-vivo model for studying human gastro-enteritis caused by $S$. enterica serotype Typhimurium is the rhesus monkey. However, the early events of severe ileitis in infected monkeys can be mimicked in the rabbit ileal loop (RIL) model [10-12]. From this model, an in-vitro asymmetric organ culture technique (rabbit ileal invasion assay, RIIA) was developed for quantitative assessments of invasiveness of enteric pathogens for rabbit ileal enterocytes in situ [13-16] and the demonstration of a salmonella histotoxin [17]. In the present study, the RIIA has been adapted to select gut-invasive phenotypes from a cosmid library of genomic DNA constructed from the invasive $S$. Typhimurium strain TML [10] and maintained in an avirulent hypo-invasive $S$. Typhimurium strain LT7 [18].

Salmonella cells can be translocated directly to the bloodstream by phagocytes [19] or can directly invade $\mathrm{M}$ cells and enterocytes $[8,9,13]$. The objective of these studies was the elucidation of biological mechanisms and microbial determinants responsible for invasion and subsequent perturbation of enterocytes. Therefore, a strategy was designed to identify salmonella determinants of direct invasion of enterocytes without prejudice as to which, if any, SPIs were involved. A size-fractionated library was constructed [20] containing 40-kb fragments of genomic DNA from strain TML which were then introduced into strain LT7.

Strains TML and LT7 were selected for this work because they had been well characterised in RILs [21] and the RIIA [13], were non-histotoxic for rabbit terminal ileum [17], had the same plasmid profiles [22], and had not been genetically manipulated. A chromosomally derived recombinant clone, designated LT7(pHC20.2), was isolated which was analysed under different conditions for its invasiveness for gut explants and Caco-2 cells, growth characteristics, electron microscopic appearance and expression of surface proteins.

\section{Materials and methods}

\section{Bacterial strains, plasmids and media}

The four Salmonella strains - TML [10], LT7 [18], LT7(pHC79) and TNP-5 - were grown routinely in Hartley Digest Broth (HDB; Public Health Laboratory, London) or on MacConkey agar (MCA) without added salt and crystal violet (Becton Dickinson, Cockeysville, USA) plates. Strain TNP-5 is a nalidixic acid- and carbenicillin-resistant derivative of strain TML whose invasiveness is the same as parental TML [15]. Where applicable, carbenicillin $(\mathrm{Cb} ; 250 \mathrm{mg} / \mathrm{L})$ was used to select and maintain the cosmid vector pHC79 [23] and its derivatives.

\section{Production of the library}

Construction of the genomic library of strain TML in the Cb-resistant cosmid pHC79, and its transformation into and maintenance in strain LT7 were as described previously [20]. Briefly, 30-40-kb Sau3AI-restricted genomic DNA from $S$. Typhimurium TML was ligated into $\mathrm{pHC} 79$. Recombinants were packaged into $\lambda$ particles and transfected into Escherichia coli HU835. Because smooth strains of $S$. Typhimurium such as LT7 cannot be infected with $\lambda$ it was necessary to repackage the library into Typhimurium bacteriophage P22 via $S$. Typhimurium strain AS68 which has both $\lambda$ and P22 receptors, before transduction into LT7 and selection for Cb-resistant colonies [24].

\section{Rabbit ileal invasion assay}

This was performed as described previously [13]. Briefly, rabbit ileal mucosa was mounted into an organ culture apparatus such that the mucosal and serosal sides were bathed in mucosal and serosal solutions, respectively, which were designed to maintain the viability of both the tissue and bacteria over the duration $(3 \mathrm{~h})$ of an assay. Bacterial suspensions were added to the mucosal side of the tissue. After $2 \mathrm{~h}$, extracellular bacteria were killed by incubation for $1 \mathrm{~h}$ at $37^{\circ} \mathrm{C}$ with fresh medium supplemented with gentamicin $(100 \mathrm{mg} / \mathrm{L})$. A 12-mm disk was cut from the tissue removed from the apparatus and, after rinsing, the disk was homogenised in $2 \mathrm{ml}$ of standard phosphate-buffered saline (PBS) to release intracellular bacteria; $1 \mathrm{ml}$ of Triton X-100 (1\% v/v in PBS) was added to the homogenised tissue to aid release of intracellular bacteria. Viable counts were then performed by plating serial dilutions of tissue homogenate on MCA.

\section{Preparation of inocula for RIIA experiments}

Standard preparation. Inocula were derived by inoculating single colonies of each strain from MCA plates into separate $10-\mathrm{ml}$ volumes of HDB followed by static incubation at $37^{\circ} \mathrm{C}$ for $16 \mathrm{~h}$. Organisms were harvested by centrifugation $\left(1800 \mathrm{~g}, 10 \mathrm{~min}, 20^{\circ} \mathrm{C}\right)$ and resuspended in $5 \mathrm{ml}$ of fresh $\mathrm{HDB}$, of which $1 \mathrm{ml}$ was used to inoculate $90 \mathrm{ml}$ of $\mathrm{HDB}$ which was then grown statically for $2.5 \mathrm{~h}$ at $37^{\circ} \mathrm{C}$ to generate log-phase bacteria. Up to this point the procedure was standard. Organisms were then centrifuged $(1800 \mathrm{~g}, 10 \mathrm{~min}$, $20^{\circ} \mathrm{C}$ ) and resuspended in $5 \mathrm{ml}$ of mucosal medium [13]. Inoculum sizes for different strains to be tested in any one RIIA were standardised by performing total counts on each culture followed by adjustment to $c$. $1 \times 10^{8}$ cells $/ \mathrm{ml}$; viable counts were also performed.

Validation of the RIIA as an enrichment/selection system. For the initial inoculum, the standard procedure was followed, then the two strains (TNP-5 and LT7) were mixed in the required ratio to give a final 
total count of $c .1 \times 10^{8}$ cells $/ \mathrm{ml}$; viable counts were also performed.

Enrichment/selection of invasive phenotypes. Initial 'library inocula' were generated as follows. Assuming a randomly representative library, 562 clones should have been sufficient for a $99 \%$ probability of any genomic sequence being present in a cosmid library constructed from 40-kb fragments [25]. However, to maximise the probability of finding any genomic sequence in the starting inoculum for the passage experiment, c. $3000 \mathrm{Cb}^{\mathrm{R}}$ library colonies were scraped into $1 \mathrm{ml}$ of HDB with a sterile spreader; $10 \mu \mathrm{l}$ of this suspension were used to inoculate $10 \mathrm{ml}$ of HDB supplemented with $\mathrm{Cb}$ and EGTA (5 mM EGTA was included to prevent P22 entering its lytic cycle); this suspension was subsequently incubated statically at $37^{\circ} \mathrm{C}$ for $16 \mathrm{~h}$. The library culture was then treated as described above (standard procedure).

\section{Invasion experiments}

Validation of the RIIA as an enrichment/selection system. In the experiments designed to validate the system, the RIIA system was used [13], with the following modifications. For the first assay a mixture of strains TNP-5 and LT7 was used as inoculum; LT7 was the predominant strain in the mixture. Before addition of gentamicin to kill extracellular organisms, a sample of chamber fluid was withdrawn for a duplicate set of viable counts on MCA and $\mathrm{Cb}$ MCA to determine the ratio of LT7 : TNP-5. After washing, the ratio of tissueprotected LT7:TNP-5 was also measured in tissue homogenates; a second assay was performed with strains LT7 and TNP-5 in which this ratio was used. The procedure was repeated a third time.

Enrichment/selection of invasive phenotypes. Enrichment/selection of recombinants from the TML library in LT7 was based on iterative passage of organisms through the RIIA. The inoculum for the first pass was prepared as described above. After the first pass, gentamicin-treated ileal tissue from each of the chambers [13] was homogenised separately. Inocula (library and controls) for the second and subsequent passes were prepared from pooled 3-ml volumes of homogenate from each of three replicate chambers. Homogenates were pelleted by centrifugation $(1800 \mathrm{~g}$, $10 \mathrm{~min}, 20^{\circ} \mathrm{C}$ ); bacteria and pelleted gut-debris were resuspended in $10 \mathrm{ml}$ of HDB supplemented, where appropriate, with $\mathrm{Cb}$ and EGTA. The suspensions were incubated without shaking at $37^{\circ} \mathrm{C}$ overnight from which log-phase inocula were generated and appropriately adjusted numerically as described above. This overnight growth step was dictated by the dynamics of the RIIA system [13]. It is possible to maintain the structural and functional integrity of the gut explants for a maximum of $4 \mathrm{~h}$; for this reason the tests are limited to $3 \mathrm{~h}$. Optimal inoculum size is c. $1 \times 10^{8} \mathrm{cfu} / \mathrm{chamber}$, which results in the intern- alisation of c. $10 \%$ of the inoculum for hyperinvasive strains. If the number of invasive organisms present in the initial mixture is low - as would be anticipated in the library - the number of tissue-protected organisms recovered will be very low. This means that expansion of the tissue-protected population is necessary - at least in the early cycles - to minimise the number of subsequent cycles of enrichment.

\section{Restriction endonuclease analysis}

Colonies were selected at random from the library and cosmid DNA was extracted and cleaved with HindIII restriction endonuclease by standard techniques [26]; fragmented DNA was separated by electrophoresis. A similar procedure was performed on randomly selected colonies from each pass and restriction patterns of different cosmids were compared.

\section{Caco-2 cell culture}

Ten-to-twelve day post-confluent Caco-2 cell monolayers were prepared and used for invasion assays as described previously [27] and for providing growthinducing conditions and protein analyses (see below).

\section{Electron microscopy}

Samples $(100 \mu \mathrm{l})$ were taken from the chamber fluid at various time points. These were mixed immediately with $1 \mathrm{ml}$ of glutaraldehyde fixative $(2.5 \% \mathrm{v} / \mathrm{v}$ in phosphate buffer, $\mathrm{pH} 7.2$ ) in a $1.5-\mathrm{ml}$ plastic tube; bacteria were pelleted by centrifugation. For tissueassociated bacteria samples were prepared as described previously [27].

\section{Preparation and invasiveness of gut-conditioned strains LT7, LT7(pHC20.2) and LT7(pHC79)}

In a series of experiments, LT7, LT7(pHC20.2) and LT7(pHC79) organisms were grown overnight in the presence of gut homogenate. This was to mimic the conditions in the RIIA passage experiments in which overnight expansion of bacterial numbers (for the production of passage inocula) occurred in tissue homogenate residues. In these experiments, homogenate from $150 \mathrm{~mm}^{2}$ of rabbit ileal tissue was added to $10 \mathrm{ml}$ of HDB (equivalent to the tissue recovered from three chambers in the RIIA) in which organisms were incubated at $37^{\circ} \mathrm{C}$ for $16 \mathrm{~h}$. Cultures prepared in this way are referred to as gut-conditioned. The invasiveness of gut-conditioned organisms for ileal explants and Caco-2 cells was examined.

\section{Growth characteristics of Salmonella strains in the presence of ileal explants or Caco-2 cells}

To examine the growth of Salmonella strains in the presence of gut tissue, a bacterial suspension in log phase, prepared in mucosal medium as described for 
the RIIA, was added to RIIA chambers with or without fresh gut tissue. Samples were taken every $30 \mathrm{~min}$ and viable counts were made.

For purely logistical reasons, use was made of gut-derived Caco-2 cells in which most of the characteristics important in the early interaction of $S$. Typhimurium with gut epithelia have been reproduced [27]. Inocula were prepared in a manner identical to that for the RIIA up to the final suspension, for which tissue culture medium was used instead of mucosal medium. Equal volumes of this suspension were then added to a Caco- 2 cell monolayer or a fresh tissue culture flask without Caco-2 cells. Triplicate samples were taken every $30 \mathrm{~min}$ and viable counts were made. All Caco-2 cell experiments were performed in triplicate. The data presented are the means and SD of the numbers of viable bacteria from three experiments, plotted on a linear scale.

\section{Protein analyses}

All protein preparations were analysed by SDS-PAGE [28], with polyacrylamide $10 \%$ gels. After electrophoresis, gels were stained with Coomassie Brilliant Blue stain for $1 \mathrm{~h}$ and destained (glacial acetic acid, 7.5\% methanol, 10\%). Where stated, the relative amounts of protein in different samples as resolved by SDS-PAGE were evaluated by Image Master densitometry software version 1.0 (Pharmacia LKB Biotech).

Total cell proteins. Log-phase cultures grown in HDB were harvested by centrifugation $(1800 \mathrm{~g}, 10 \mathrm{~min}$, $20^{\circ} \mathrm{C}$ ) and resuspended in $200 \mu \mathrm{l}$ of PBS. The suspensions were optically standardised (at $600 \mathrm{~nm}$ ). Samples were diluted in SDS-PAGE sample buffer and analysed by SDS-PAGE.

Inner- and outer-membrane proteins (OMPs). Organisms were grown as for total cell protein analyses. Outer and inner membranes were separated by isopycnic sucrose density gradient ultracentrifugation [29]. For logistical reasons, membranes from strains grown in the presence and absence of gut homogenate were isolated on different days, but equivalent numbers of organisms (based on total counts) were used for each strain. Organisms (c. $1.25 \times 10^{10}$ bacteria) were harvested by centrifugation $\left(1800 \mathrm{~g}, 10 \mathrm{~min}, 20^{\circ} \mathrm{C}\right)$ and resuspended in $900 \mu \mathrm{l}$ of sucrose-Tris $(0.75 \mathrm{M}$ sucrose, $10 \mathrm{mM}$ Tris-HCl, $\mathrm{pH} 7.8$ ) solution. After adding $90 \mu \mathrm{l}$ of lysozyme $(2 \mathrm{mg} / \mathrm{ml})$ and incubation on ice for 2 min, organisms were diluted by drop-wise addition of $1.8 \mathrm{ml}$ of ice-cold $1.5 \mathrm{mM}$ EDTA under the meniscus of the suspension over a period of $8 \mathrm{~min}$.

Samples were sonicated in a capped 28-ml container in a cup-horn sonicator (Heat Systems Ultrasonic, New York, USA) for $8 \mathrm{~min}$; intact organisms and cellular debris were removed by centrifugation $(1800 \mathrm{~g}, 10 \mathrm{~min}$, $\left.4^{\circ} \mathrm{C}\right)$. The supernate was collected and ultracentrifuged
(259000 g, TLS-55 swing-out rotor, $2 \mathrm{~h}, 4^{\circ} \mathrm{C}$ in a Beckman ultracentrifuge). Supernate was removed and the pellet containing the total membrane fraction was resuspended in $200 \mu \mathrm{l}$ of cold sucrose-Tris-EDTA (STE; $0.25 \mathrm{M}$ sucrose, $3.3 \mathrm{~mm}$ Tris-HCl, $1 \mathrm{~mm}$ EDTA), the volume was adjusted to $2.5 \mathrm{ml}$ with STE, and the sample was ultracentrifuged $\left(259000 \mathrm{~g}, 2 \mathrm{~h}, 4^{\circ} \mathrm{C}\right)$. The supernate was again removed and the pellet was resuspended in $200 \mu \mathrm{l}$ of sucrose $25 \% \mathrm{w} / \mathrm{v}$ in $5 \mathrm{mM}$ EDTA. This was layered on to a step-wise sucrose gradient ranging from $65 \%$ to $30 \% \mathrm{w} / \mathrm{v}$ in $5 \mathrm{mM}$ EDTA and ultracentrifuged $\left(214000 \mathrm{~g}, 16 \mathrm{~h}, 4^{\circ} \mathrm{C}\right) ; 270-\mu \mathrm{l}$ fractions were removed and stored at $-20^{\circ} \mathrm{C}$ before analysis by SDS-PAGE. Inner-membrane proteins were contained in the low-density fractions and outermembrane proteins in the high-density fractions.

Surface structure proteins. Starting cultures were grown as described for $\mathrm{Caco}-2$ cell growth experiments. Approximately $4 \times 10^{8}$ organisms resuspended in tissue culture medium were used to infect 10-12day post-confluent monolayers (or wells without Caco2 cells), the supernate was removed and surface structures were prepared by physical shearing as follows [30]. Bacteria $\left(1 \times 10^{10}\right)$ were harvested by centrifugation $\left(1800 \mathrm{~g}, 10 \mathrm{~min}, 20^{\circ} \mathrm{C}\right)$ and resuspended in $3 \mathrm{ml}$ of HDB. The suspension was transferred to an Omnimixer (Sorvall, Newtown, CT, USA) bucket and homogenised on full power for $30 \mathrm{~s}$. The suspension was divided between two microfuge tubes and centrifuged $\left(15400 \mathrm{~g}, 2.5 \mathrm{~min}, 20^{\circ} \mathrm{C}\right) ; 2.5 \mathrm{ml}$ of the combined supernate was taken and made $1 \% \mathrm{v} / \mathrm{v}$ with respect to Triton X-100, and ultracentrifuged $\left(137000 \mathrm{~g}, 1 \mathrm{~h}, 20^{\circ} \mathrm{C}\right)$. Pellets were resuspended in $100 \mu \mathrm{l}$ of PBS, left for $c .10 \mathrm{~min}$ at $20^{\circ} \mathrm{C}$ to facilitate resuspension, then stored at $-20^{\circ} \mathrm{C}$ until required.

\section{$N$-Terminal sequencing of proteins}

Proteins were transferred to polyvinylidine difluoride membranes (Amersham) by electroblotting in a semidry blotting apparatus (Pharmacia). The protein was sequenced by the Edman degradation method on an Applied Biosystems 437A machine.

\section{DNA sequencing}

Deletion derivatives of $\mathrm{pHC} 20 \cdot 2$ were constructed by restriction digestion, with enzymes that had a single recognition site in the vector $\mathrm{pHC79}$ and at least one further site in $\mathrm{pHC} 20 \cdot 2$, followed by re-circularisation by ligation and transformation into $E$. coli $\mathrm{DH} 5 \alpha$. Primers were designed which anneal to sequences in the vector pHC79 and initiate DNA synthesis into the insert: 5'-GCCACCTGACGTCTAAGAAACC-3', and 5'-CAACCGCACCTGTGGCGCCGG-3'. Approximately $400 \mathrm{bp}$ of sequence was derived from each deletion derivative on a Perkin Elmer/ABI 373A instrument, by AmpliTaq FS dye terminator chemistry. Programmes from the Wisconsin Package Version 10, 
Genetics Computer Group (GCG) [31] were used. FASTA [32] searches were performed against the combined GenBank and EMBL database. BLAST 2.0 was used against the NCBI BLAST database.

\section{Mapping of the position of $\mathrm{pHC} 20 \cdot 2$ on the chromosome}

Genomic DNA was prepared in agarose blocks from $S$. Typhimurium strains TML and LT2, and digested with either $B \ln \mathrm{I}$ or $X b a \mathrm{I}$. Fragments were separated by pulsed-field gel electrophoresis in a CHEF DR II system (BioRad UK) on an agarose $1 \%$ gel. Initially the gels were run at $4.8 \mathrm{~V} / \mathrm{cm}$ with a ramp time of $10-100 \mathrm{~s}$ for $48 \mathrm{~h}$ in $0.5 \times \mathrm{TBE}(45 \mathrm{mM}$ Tris-borate, $1 \mathrm{mM}$ EDTA). For better resolution of the high mol. wt bands the ramp time was altered to $40-100 \mathrm{~s}$. DNA was transferred to a positively charged nylon membrane (Boehringer Mannheim) by downward alkaline transfer with denaturing solution $(0.5 \mathrm{M} \mathrm{NaOH}, 1.5 \mathrm{M}$ $\mathrm{NaCl}$; [33]) for $24 \mathrm{~h}$. The filter was neutralised by washing for $5 \mathrm{~min}$ in neutralising solution $(0.5 \mathrm{M}$ Tris, $1.5 \mathrm{M} \mathrm{NaCl})$ and stored dry until required.

\section{Southern hybridisation}

Digoxigenin (DIG) labelling of DNA probes was done by random prime incorporation [34] of DIG dUTP, with linearised DNA as a template (Boehringer Mannheim) and detected with a DIG luminescent detection kit according to the manufacturer's instructions (Boehringer Mannheim). Southern hybridisation was performed by standard techniques [35] and hybridised DNA was detected by chemiluminescence of DIG with a DIG luminescent detection kit obtained from Boehringer Mannheim.

\section{Results}

Validation of the RIIA as an enrichment/selection system

Two experiments, each involving three consecutive RIIAs were performed. The initial mixed inocula contained $0.19 \%$ and $0.14 \%$ of strain TNP-5, respectively. The final tissue-protected organism populations after three RIIAs consisted of strain TNP-5 (104 SD $10 \%$ and 97 SD 5\% respectively); the full combined data are summarised in Table 1 . The ratios of strains TNP-5 and LT7 did not change significantly during the 2-h growth in the chamber. Because each assay was performed on a different rabbit on a different day, it was important to monitor invasion levels of strains TNP-5 and LT7 individually in each experiment; the invasion levels of strain TNP-5 were consistently $c$. 9-fold higher than that of strain LT7 which is within the normal range $[13,22]$ thereby validating the six assays performed (data not shown). These data (Table 1) show that the RIIA system could enrich invasive clones from mixtures of invasive and hypo-invasive clones very efficiently even at low ratios of invasive to hypo-invasive organisms.

\section{Enrichment/selection of invasive phenotypes from the TML library in LT7}

An experiment involving four passes of strain LT7 carrying the library through the RIIA was perfomed with LT7(pHC79) and TML strains as hypo-invasive and fully invasive controls, respectively. In the first two passes, the recovery of bacteria carrying the library was less than that for $S$. Typhimurium LT7(pHC79) (Fig. 1). At this stage the culture was still heterogeneous (see below) and, presumably, only a very small number of invasive clones was present. The invasiveness of the library was increased by c. 6 -fold in pass 3 and 20 -fold by pass 4 with respect to the control LT7(pHC79) (Fig. 1).

Cosmids from 10 clones, randomly selected from the inoculum and from each pass, were analysed by digestion with endonuclease HindIII. The recombinants present in the starting inoculum (Fig. 2a) and after pass 1 showed a random banding pattern. Those from pass 2 (not shown) were less random, indicating that selection of certain clones had occurred during passage. In sharp contrast, plasmid profiles from recombinants from passes 3 and 4 (Fig. 2b) were identical to each other,

Table 1. Validation of rabbit ileal explants as a system for enriching gut-invasive clones from mixed populations of invasive and non-invasive $S$. Typhimurium

\begin{tabular}{|c|c|c|c|c|}
\hline \multirow[b]{2}{*}{ Experiment/assay } & \multicolumn{3}{|c|}{$\begin{array}{c}\text { Mean (SD) percentage of } S \text {. Typhimurium TNP-5 } \\
\text { in TNP-5/LT7 mixtures in }\end{array}$} & \multirow{2}{*}{$\begin{array}{c}\text { Fold increase of } \\
\text { TNP-5 in } \\
\text { homogenate }\end{array}$} \\
\hline & inoculum & chamber fluid* & homogenate $^{\dagger}$ & \\
\hline $\mathrm{E} 1 / \mathrm{A} 1^{*}$ & 0.19 & $0.17(0.02)$ & $4.02(0.83)^{\S}$ & 21 \\
\hline $\mathrm{E} 1 / \mathrm{A} 2$ & 4.6 & $2.24(0.23)$ & $54.1(0.98)$ & 12 \\
\hline $\mathrm{E} 1 / \mathrm{A} 3$ & 51.9 & $58.0(6.36)$ & $104(10)$ & 2 \\
\hline E2/A1 & 0.14 & $0.1 \quad(0.02)$ & $1.82(0.76)$ & 13 \\
\hline E2/A2 & 1.14 & $0.91(0.06)$ & $31.8(3.51)$ & 28 \\
\hline $\mathrm{E} 2 / \mathrm{A} 3$ & 31.9 & $16.7(3.51)$ & $97(5)$ & 3 \\
\hline
\end{tabular}

* Mean percentage recovery (SD) of TNP-5 from medium from three chambers.

${ }^{\dagger}$ Mean percentage recovery (SD) of TNP-5 from tissue homogenates from three chambers.

E1/A1: experiment 1, assay 1 .

${ }^{\S}$ The percentage of TNP-5 in the homogenate from each assay was used as the basis for preparation of the inoculum used in the next assay. 


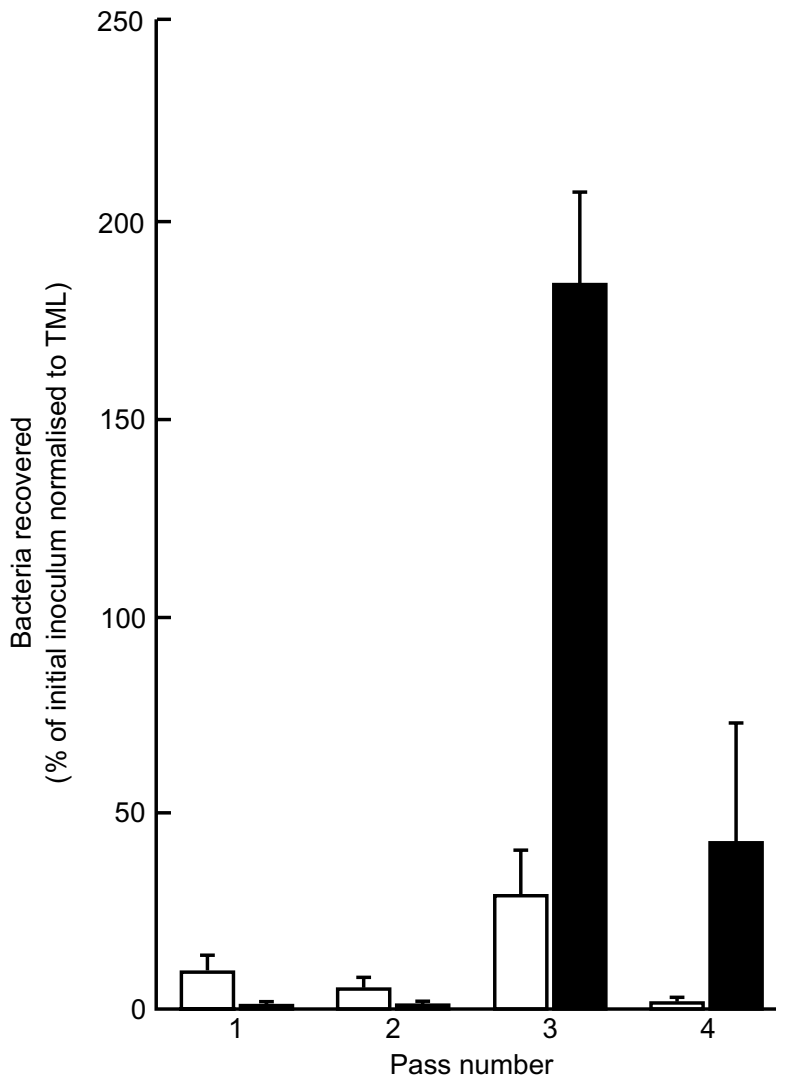

Fig. 1. Relative invasiveness of the library at passes 1-4. Each column represents the mean and SD of the numbers of tissueprotected organisms recovered from tissue homogenates from three chambers. The data are normalised to the positive control TML (100\% data not shown). $\square$, LT7(pHC79); $\mathbf{\square}$, LT7 library.

indicating that enrichment for one recombinant, designated $\mathrm{pHC} 20 \cdot 2$, had occurred. The appearance of pHC20.2 correlated with the increased invasiveness observed during passage, suggesting that the sequences responsible for the enhanced invasion were contained within $\mathrm{pHC} 20 \cdot 2$.

Invasiveness of gut-conditioned LT7(pHC20-2) in the RIIA and Caco-2 cells

In three separate experiments, single colonies of $S$. Typhimurium LT7(pHC20.2) recovered from organisms directly obtained from pass 4 were used to generate inocula for a RIIA with standard media and growth protocols, and tested against control $S$. Typhimurium strains, TML, and LT7(pHC79). In these experiments, there was no significant difference between invasiveness of $\mathrm{LT} 7(\mathrm{pHC} 20 \cdot 2)$ and that of LT7(pHC79) (data not shown).

The major difference between the treatment of organisms during the passage experiment and the single colony invasion experiments described above was perceived to be in the preparation of inocula. Passage inocula were grown in HDB, which contained residual gut homogenate from the previous assay. Therefore, cultures derived from single colonies were grown overnight in HDB in the presence of gut (gut-
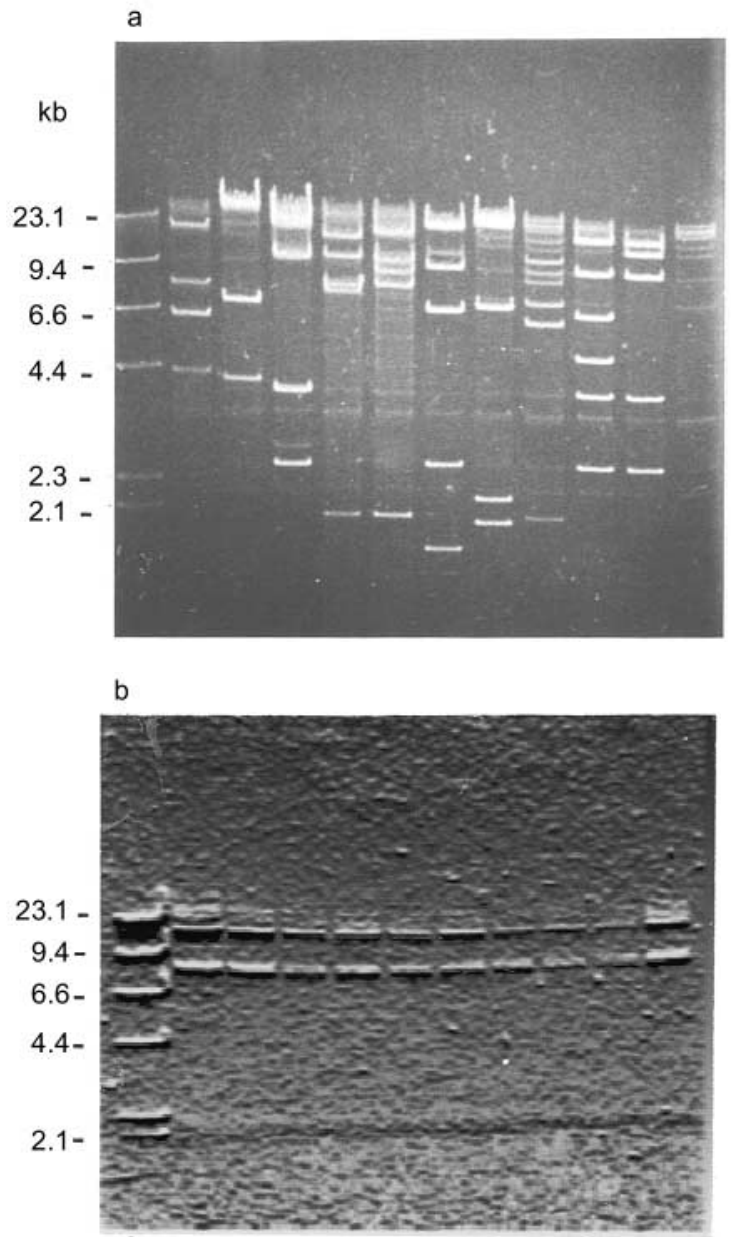

Fig. 2. HindIII-restriction analysis of plasmid DNA from randomly selected library recombinants from (a) the inoculum and (b) pass 4 (presented in 'relief' for clarity). Lanes (from left): (a) 1, $\lambda$ HindIII mol. wt markers; 2-11, randomly selected library recombinants; 12, LT7; (b) 1, $\lambda$ HindIII mol. wt markers; 2-11, library recombinants.

conditioned). In three RIIA experiments, the invasiveness of gut-conditioned LT7 $(\mathrm{pHC} 20 \cdot 2)$ increased to that observed during passaging, but gut-conditioning did not affect the invasiveness of LT7(pHC79) (Fig. 3) or of LT7 (not shown). Although the absolute values of invasiveness differed between experiments because of inter-animal tissue variations, the patterns of relative invasiveness remained the same. A significant difference was noted between LT7( $\mathrm{pHC} 20 \cdot 2)$ with gutconditioning compared with either LT7(pHC20 2) without gut-conditioning or LT7(pHC79) with or without gut-conditioning ( $\mathrm{p}<0.05$, Student's $t$ test).

The possibility was considered that the increased invasiveness of LT7(pHC20.2) was due to acquisition of increased gentamicin resistance of adherent noninternalised organisms during the invasion assay and not to protection from gentamicin afforded by internalisation within enterocytes. However, this was shown not to be the case: gentamicin $50 \mathrm{mg} / \mathrm{L}$ caused a 5 $\log _{10}$ reduction in the viability of both LT7(pHC79) and LT7(pHC20.2), irrespective of gut-conditioning. 


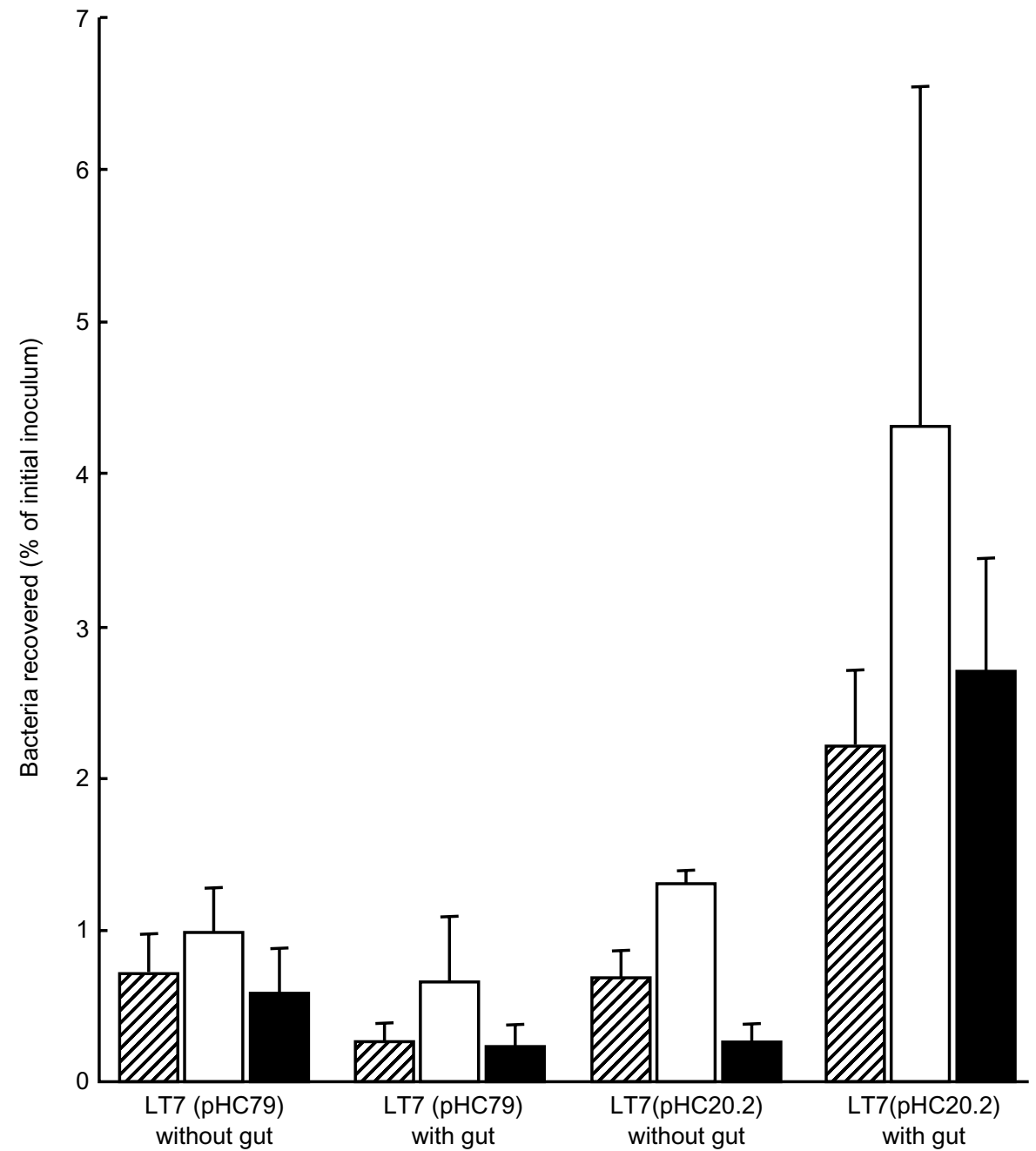

Fig. 3. The effect of gut-conditioning of inocula on invasion. For three RIIA experiments, LT7(pHC20.2) and LT7(pHC79) inocula were prepared by overnight growth in the presence or absence of gut homogenate. The invasiveness of one set of four inocula was compared in gut from one animal (represented by similarly shaded bars). In each experiment the invasiveness of LT7(pHC20.2) was increased by gut-conditioning both in absolute terms and relative to LT7(pHC79). Each column is the mean and SD of the numbers of tissue-protected organisms recovered from tissue homogenates from three chambers.

A similar effect was seen when invasiveness was assayed in cultured cells; gut-conditioning enhanced the invasiveness of $\mathrm{LT7}(\mathrm{pHC} 20 \cdot 2)$ but not of LT7 or LT7(pHC79), for Caco-2 cells by $c$. two-fold (data not shown).

Growth of gut-conditioned LT7(pHC20-2) in the presence and absence of Caco-2 cells

Three experiments with Caco-2 cells were performed over $2.5 \mathrm{~h}$ (Fig. 4). The growth of LT7(pHC79) was unaffected by the presence of Caco- 2 cells; it was also greater than the growth of LT7(pHC20.2) in the absence of Caco- 2 cells, which could be ascribed to differential plasmid burdens $(6.4 \mathrm{~kb}$ and c. $40 \mathrm{~kb}$, respectively), but this possibility was not formally tested. For LT7(pHC20.2) there was no difference in growth in the presence or absence of Caco-2 cells up to $1 \mathrm{~h}$. After $1.5 \mathrm{~h}, \mathrm{LT} 7(\mathrm{pHC} 20 \cdot 2)$ exhibited continued growth in the presence of Caco- 2 cells. At $2.5 \mathrm{~h}$, the level of growth of LT7(pHC20.2) (not gut-conditioned) in the presence of Caco-2 cells was equivalent to that of LT7(pHC79).
Growth of gut-conditioned LT7(pHC20-2) in the presence and absence of ileal explants

In one experiment, the growths of gut-conditioned LT7 $(\mathrm{pHC} 20 \cdot 2)$ and LT7(pHC79) were compared in RIIA chambers in the presence and absence of ileal mucosa. LT7(pHC20.2) grew better in the presence of gut tissue, whereas little difference was observed for LT7(pHC79). The growth pattern of LT7(pHC79) was independent of the presence of gut, and was similar to that of LT7(pHC20-2) in the presence of gut (Fig. 5).

\section{Induced changes in surface proteins of LT7 (pHC20·2)}

Expression of the invasive phenotype of LT7(pHC20 2) in both the RIIA and Caco-2 cell assay was induced by gut-conditioning. Therefore, the possibility that the inducible phenotype could be correlated to changes in protein expression was investigated. Organisms were grown overnight in HDB with and without gut homogenate. Gut-conditioning had no readily reproducible effect on the protein profiles from cul- 

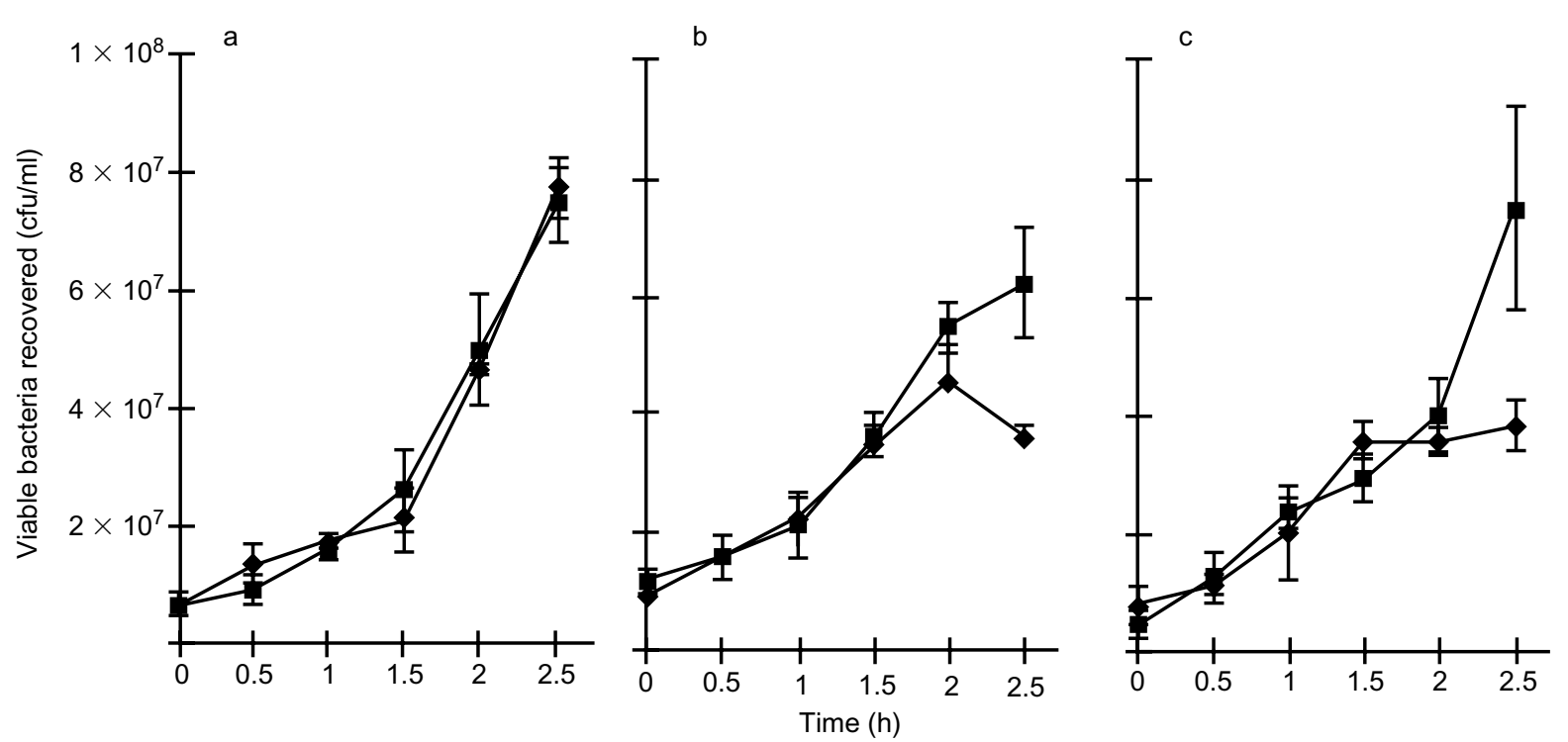

Fig. 4. The effect of gut-conditioning and exposure to Caco-2 cells on the growth of LT7(pHC79) and LT7(pHC20.2): (a) gutconditioned LT7(pHC79); (b) LT7(pHC20.2) with gut-conditioning; (c) LT7(pHC20.2) without gut-conditioning. Although differences noted between the strains grown in the presence or absence of gut-conditioning were not statistically significant, the trend was highly reproducible between experiments. $\bullet$, organisms from wells without Caco-2 cells; $\mathbf{\square}$, organisms from wells with Caco-2 cells.

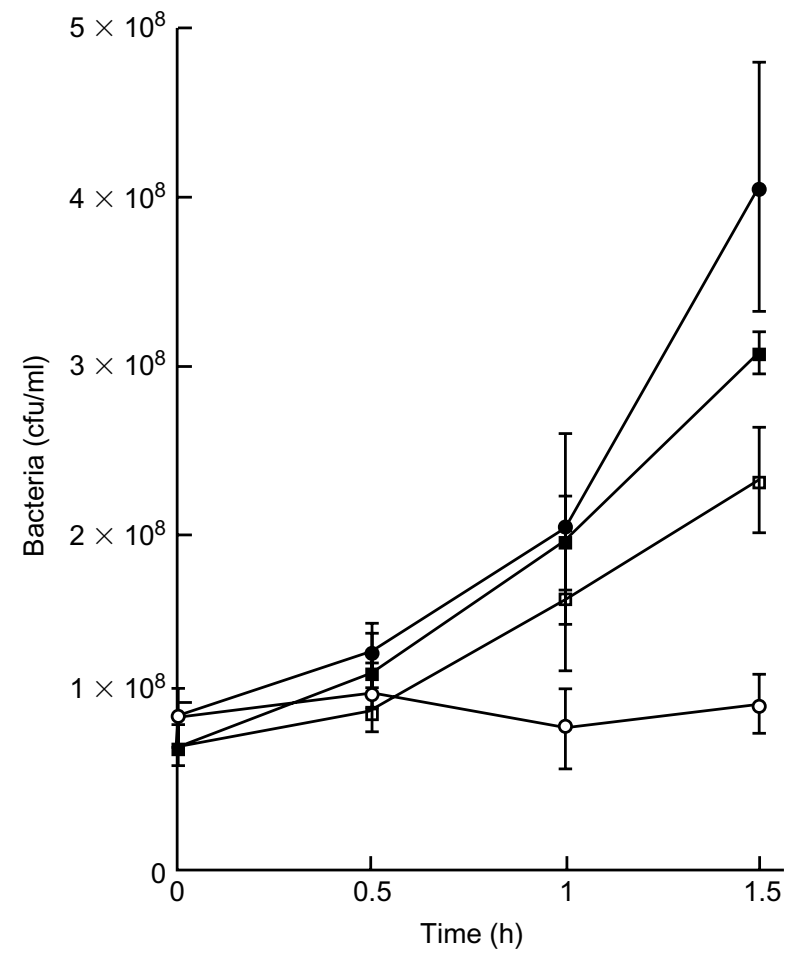

Fig. 5. The effect of rabbit ileal tissue on the growth characteristics of gut-conditioned $\mathrm{LT} 7(\mathrm{pHC} 20 \cdot 2)$ and $\mathrm{LT} 7(\mathrm{pHC} 79)$ Data are the mean and SD of the concentration of viable bacteria sampled from the chamber fluid and are plotted on a linear scale; triplicate chambers were sampled at each time point. $\square$, LT7(pHC79) with no gut in chamber; LT7(pHC79) with gut in chamber; $\bigcirc$, LT7 $(\mathrm{pHC} 20 \cdot 2)$ with no gut in chamber; $-\operatorname{LT} 7(\mathrm{pHC} 20 \cdot 2)$ with gut in chamber. As only one experiment was carried out no statistical analyses were done. ture supernates, whole cells or inner membranes in S. Typhimurium TML, LT7, LT7(pHC79) or LT7 (pHC20.2) (data not shown).

In contrast, outer membranes did reveal differences in protein profiles (Fig. 6a). Inspection of profiles from gut-conditioned organisms revealed the following (Fig. 6a, lanes 2, 4, 6 and 8): (i) induction of a 47-kDa protein; (ii) repression of a $49.5-\mathrm{kDa}$ protein; (iii) varying levels of a 52-kDa protein (see below); and (iv) reduced expression of a triplet of proteins. The $\mathrm{N}$-terminal sequence of the largest of the triplet of proteins (Gln-Ile-Tyr-Asn-Lys-Asp-Gly-Asn-) was 85\% identical with that of the first eight amino acids of the mature form of proteins from the family of porin proteins which includes OmpF and OmpC. This, together with its molecular size $(41.2 \mathrm{kDa})$, indicated that it was OmpF. Based on molecular sizes, the other two proteins could be OmpC $(40.0 \mathrm{kDa})$ and $\mathrm{PhoE}$ $(38.7 \mathrm{kDa})$. Inspection of profiles from organisms not pre-grown in gut homogenate revealed the following (Fig. 6a, lanes 3, 5, 7 and 9): (i) OmpF (41.2 kDa) was more abundant in $S$. Typhimurium TML and LT7 (pHC20.2) than in LT7 and LT7(pHC79); (ii) OmpC (40 kDa) was more abundant in $S$. Typhimurium LT7 and LT7(pHC79) than in TML and possibly LT7(pHC20.2); (iii) a 49.5-kDa protein was observed in all strains but this was not characterised.

\section{Induced changes in flagellin production}

In HDB medium. Transmission electron micrographs of bacteria grown in HDB to log phase, indicated that they possessed various surface structures, including 


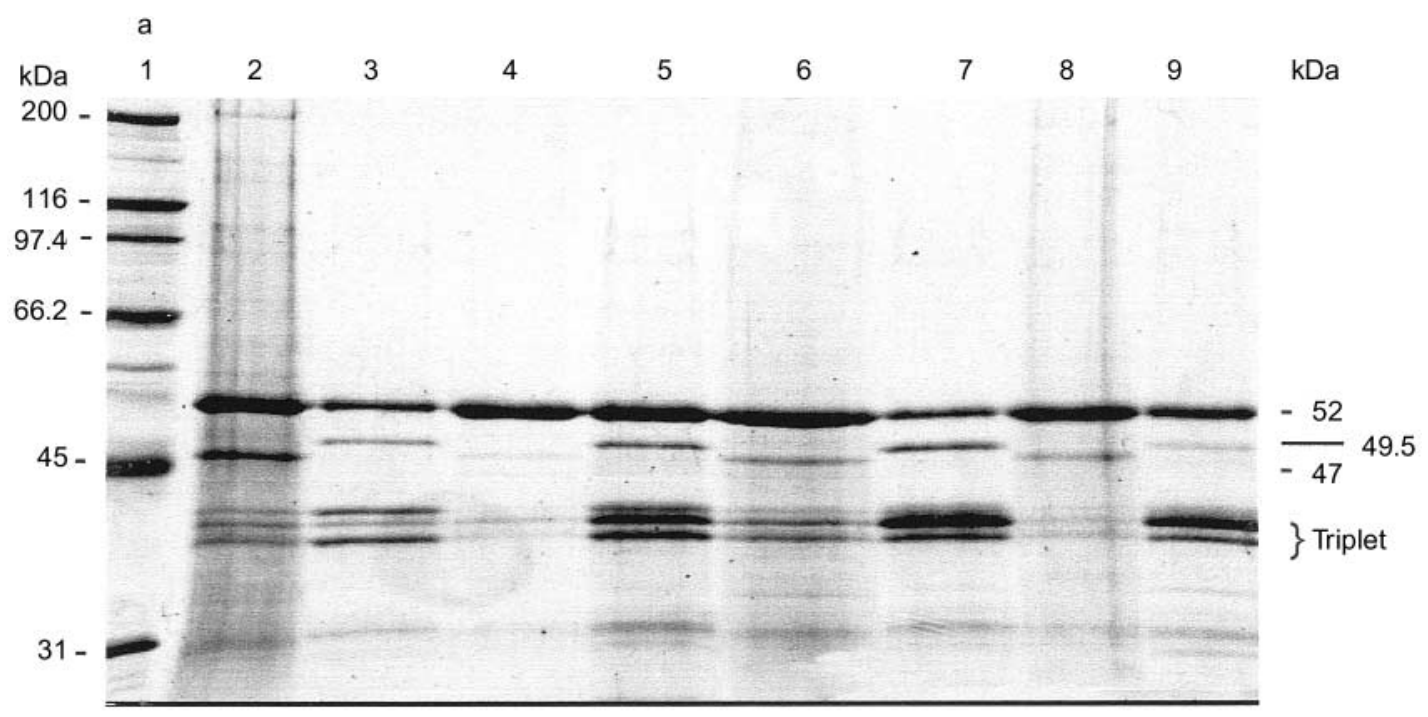

b

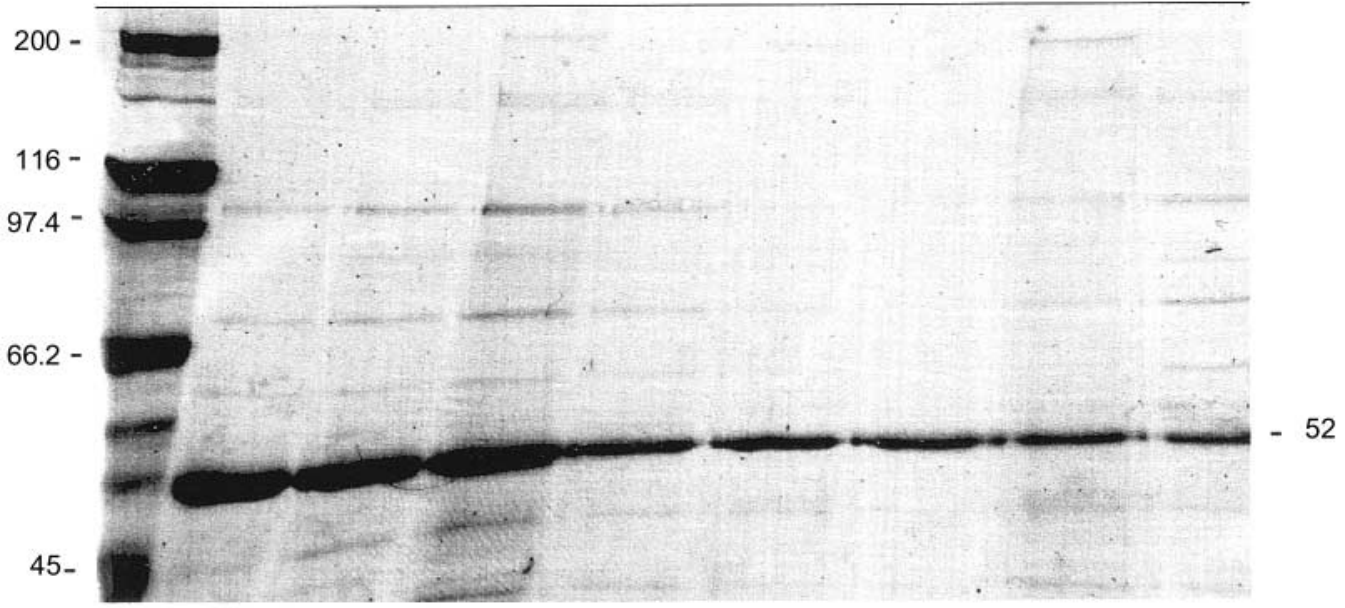

Fig. 6. Surface proteins of organisms with or without gut-conditioning. (a) Outer-membrane protein profiles; (b) surface structure proteins. Lanes: 1, mol. wt markers; 2, TML +; 3, TML-; 4, LT7(pHC20.2)+; 5, LT7(pHC20·2)-; 6, LT7(pHC79)+; 7, LT7(pHC79)-; 8, LT7+; 9, LT7-. +, gut-conditioned; -, not gut-conditioned.

flagella, pili and other appendages (data not shown). From this point, the term appendage is used to designate the 60-70-nm diameter structures seen in SEM. Surface structures were therefore isolated by mechanical shearing and ultracentrifugation, and analysed by SDS-PAGE (Fig. 6b). Striking differences in the amounts of the $52-\mathrm{kDa}$ protein were observed. $S$. Typhimurium TML (independent of gut-conditioning) and gut-conditioned LT7(pHC20.2) exhibited equivalent levels of the $52-\mathrm{kDa}$ protein, as judged by visual inspection. In contrast, non-gut-conditioned $S$. Typhimurium LT7(pHC20.2) and both LT7 and LT7(pHC79), independent of gut-conditioning, expressed a reduced amount of this protein. It was concluded that the expression of a surface-located 52$\mathrm{kDa}$ protein in $\mathrm{LT} 7(\mathrm{pHC} 20 \cdot 2)$, grown under conditions which induced an invasive phenotype, was upregulated. $\mathrm{N}$-Terminal sequencing of the $52-\mathrm{kDa}$ protein showed that the first 10 amino acids were Ala-Glu-Val-Ile-AsnThr-Asn-Ser-Leu-Leu-, which is identical to the se- quence of $S$. Typhimurium flagellin FliC (accession no. D13689 [36]). In $S$. Typhimurium the mol. wt of flagellin, the subunit of flagella, varies between 51 and $56 \mathrm{kDa}$ [37].

By qualitative TEM analysis, gut-conditioned LT7 (pHC20.2) could not be seen to possess more flagella than either LT7(pHC20.2) pre-grown without gut homogenate overnight or LT7(pHC79) (not shown).

In the presence of Caco-2 cells. Attempts to demonstrate changes in the surface proteins of cell-associated bacteria by SDS-PAGE were unsuccessful because of lysis of Caco-2 cells resulting in a high background of Caco-2 cell proteins. Prior separation of bacteria from Caco-2 cells by osmotic lysis resulted in the release of much less than $0.1 \%$ of the total cell-associated bacteria (as estimated from viable counts), a fraction which was neither representative of the total adherent bacterial population nor large enough for meaningful 
analysis. However, non-adherent organisms in the supernate overlying the Caco- 2 cell monolayer also showed an abundance of appendages (Fig. 7a), which could be removed by shearing (Fig. $7 b$ ). Because of the growth-enhancing effect of the presence of Caco-2 cells on LT7(pHC20.2) after $1 \mathrm{~h}$ (see above) samples of organisms in the overlying supernate were taken at $1 \mathrm{~h}$ after challenge of Caco-2 cell monolayers, and appendage preparations were examined by SDS-PAGE. The relative amounts of flagellin produced in the

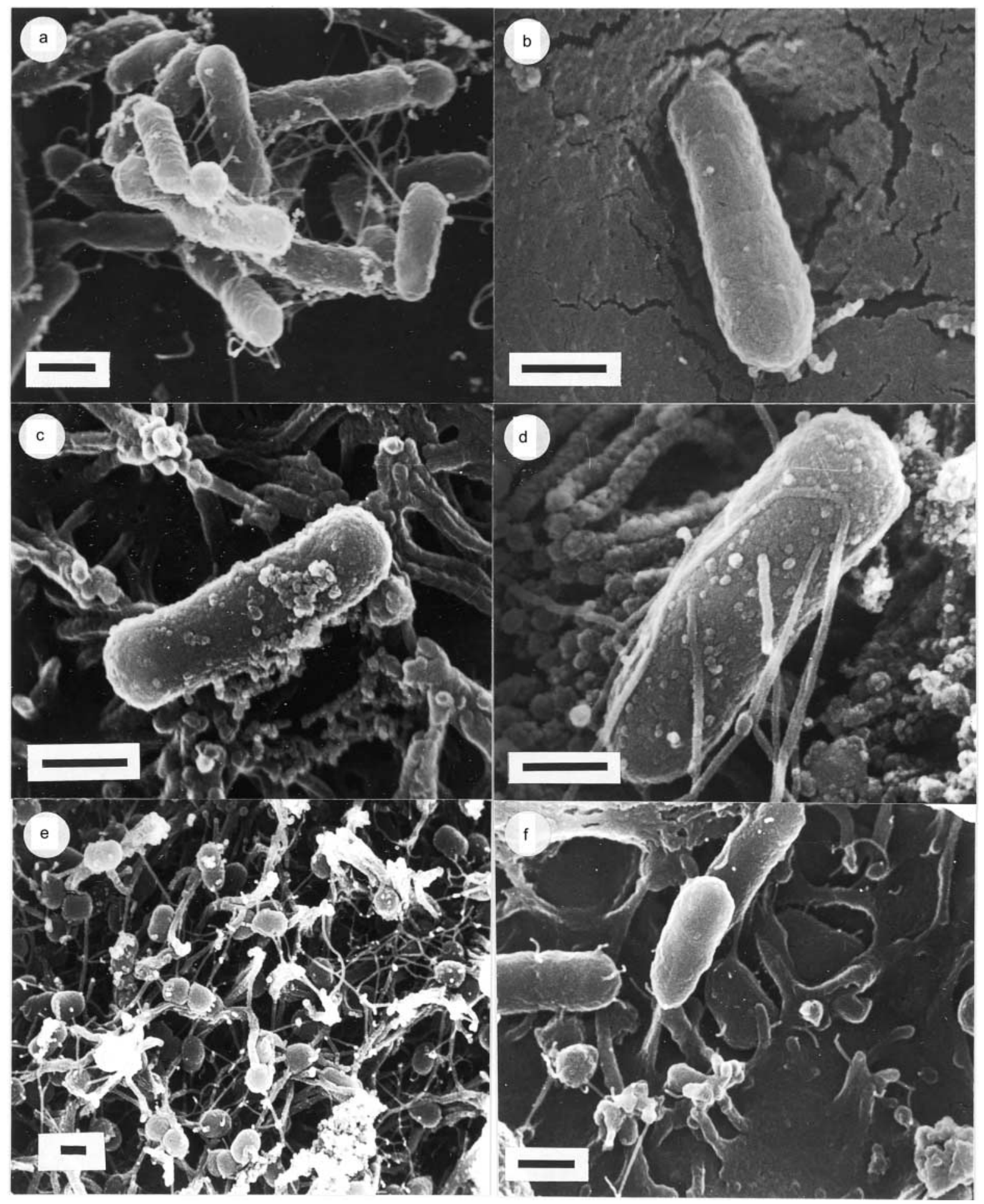

Fig. 7. SEM analysis of bacteria exposed to Caco-2 cell monolayers. a, b: gut-conditioned $S$. Typhimurium LT7(pHC20-2), sampled from the media bathing the Caco-2 cell monolayer. (a) Organisms obtained directly from monolayer supernates at $2 \mathrm{~h}$, not in direct contact with Caco-2 cells, had abundant appendages. Also, clumps of organisms with appendages emanating from bacterium to bacterium were observed. (b) A typical organism after homogenisation to release surface structures by mechanical shearing: the surface of the organism was smooth with only vestigial appendages. c, d: LT7 (pHC20·2) interacting with Caco-2 cell monolayers. Typical gut-conditioned organisms after exposure for (c) $1 \mathrm{~h}$ and (d) $2 \mathrm{~h}$ to Caco-2 cells, appendages were not seen until 2 h. e, f: $S$. Typhimurium TML interacting with Caco-2 cell monolayers. (e) After $1 \mathrm{~h}$, independent of gut-conditioning, TML expressed a mat of appendages which by $2 \mathrm{~h}$ (f) had been shed and organisms were seen entering into cells. Bars represent $0.5 \mu \mathrm{m}$. 
presence and absence of Caco- 2 cells were assessed by densitometric analysis of Coomassie-stained proteins (Fig. 8). Gut-conditioned LT7(pHC20-2) exhibited an $c$. two-fold increase in the amount of flagellin (independent of the presence of Caco-2 cells) compared with LT7(pHC20.2) pre-grown in the absence of gut homogenate overnight. However, the amount of flagellin expressed by gut-conditioned LT7(pHC20-2) was further increased by $c$. two-fold by the presence of Caco-2 cells. LT7(pHC79) did not exhibit increased amounts of flagellin under any condition.

\section{Induced changes in appendage formation}

Despite the fact that the appendages seen by scanning electron microscopy (SEM) were present before and absent after shearing, no proteins corresponding to appendages were seen in the SDS-PAGE analyses. Therefore, quantitative studies of changes in appendage expression, equivalent to those performed with flagellin, could not be done. However, it was possible to make qualitative observations by SEM on environmentally induced changes in appendage formation in both

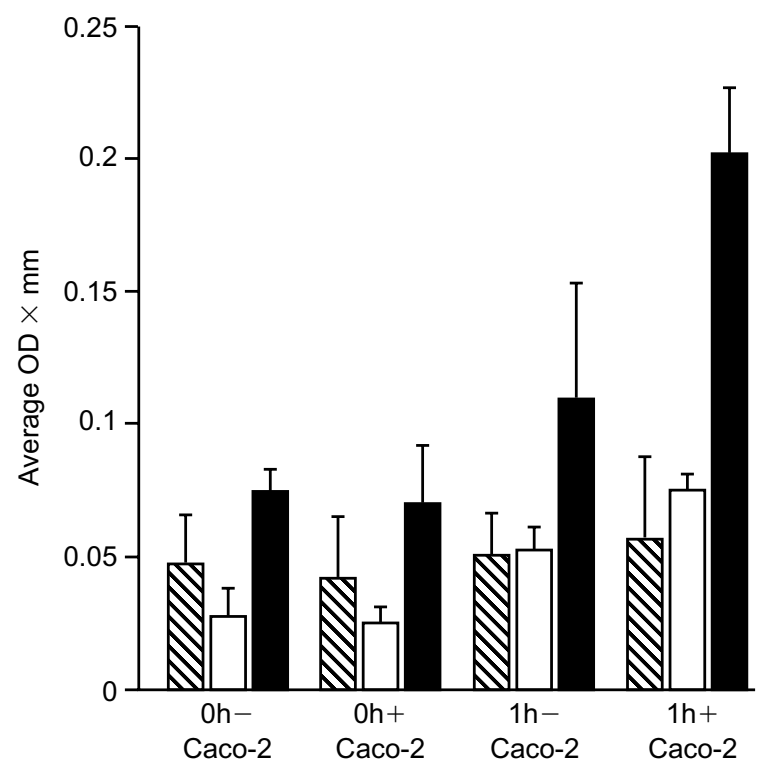

Fig. 8. Quantitative analysis of the relative amounts of $52-\mathrm{kDa}$ flagellin protein induced in the presence and absence of Caco2 cells at $0 \mathrm{~h}$ and $1 \mathrm{~h}$ after infection. Three replicate experiments were carried out. The histogram shows relative amounts of protein in different samples resolved by SDS-PAGE. The data, means and SD of three experiments, were analysed by Student's $t$ test. After $1 \mathrm{~h}$ in the presence of Caco-2 cells the amounts of flagellin induced in: (i) gut-conditioned LT7 (pHC79) were not significantly different from that induced in the absence of Caco-2 cells; (ii) both non-gut-conditioned and gut-conditioned LT7 $(\mathrm{pHC} 20 \cdot 2)$ were significantly increased compared with the corresponding values obtained in the absence of Caco- 2 cells ( $p<0.01$ and $p<0.05$ respectively); (iii) gut-conditioned $\mathrm{LT} 7(\mathrm{pHC} 20 \cdot 2)$ were significantly increased compared with (a) corresponding values obtained with no gut-conditioning $(\mathrm{p}<0.001)$ and $(\mathrm{b})$ those obtained for gut-conditioned LT7(pHC79) $(\mathrm{p}<0.005) . \mathbb{N}, \mathrm{LT} 7(\mathrm{pHC79})$ with gut; $\square, \operatorname{LT} 7(\mathrm{pHC} 20 \cdot 2)$ without gut; $\mathbf{\square}, \operatorname{LT} 7(\mathrm{pHC} 20 \cdot 2)$ with gut. cell-associated organisms and those present in the supernatant fluids of either the Caco- 2 cell assay or the RIIA.

Effects of Caco-2 cells. Gut-conditioning enhanced the invasiveness of LT7(pHC20.2) for both Caco-2 cells and rabbit ileum but the dynamics of appendage formation in LT7 $(\mathrm{pHC} 20 \cdot 2)$ and TML were different. No appendages were observed in LT7(pHC20.2) without gut-conditioning. Appendages were seen in gutconditioned LT7(pHC20.2) associated with Caco-2 cells but only after exposure for $1 \mathrm{~h}$ to the monolayers (compare Fig. 7c and d). At $1 \mathrm{~h}$ after challenge, and without the requirement for gut-conditioning, strain TML expressed a mat of appendages (Fig. 7e) which were shed as organisms entered the cells (Fig. 7f). In contrast, cell-associated $S$. Typhimurium LT7 and LT7 (pHC79), either with or without gut-conditioning, expressed no appendages in this Caco-2 cell assay by $2 \mathrm{~h}$ (not shown). What was striking, however, was the abundance of appendages expressed at $2 \mathrm{~h}$ by nonadherent LT7(pHC20-2) (Fig. 7a). Furthermore, these structures appeared to interlink adjacent bacteria (Fig. 7a).

Effects of rabbit ileal tissue. Appendage expression in enterocyte-associated LT7(pHC20.2) was evident at $2 \mathrm{~h}$ after challenge of rabbit ileal tissue in the RIIA; this did not depend on prior gut-conditioning. In contrast, internalisation of $\mathrm{LT} 7(\mathrm{pHC} 20 \cdot 2)$ by enterocytes, as judged by SEM, did require prior gut-conditioning (Fig. 9a and b), which is in agreement with the quantitative invasion data (Fig. 3). Moreover, organisms entering cells were smooth, having shed their appendages, which were readily observable in the near vicinity (Fig. 9b). In earlier work, strain LT7 was shown to express a few appendages that anchored organisms to microvilli with little perturbation of the latter, whereas strain TML expressed appendages that attached to microvilli and induced their perturbation as part of the process of internalisation; in both cases organisms were grown in rich complex media although not in the presence of gut homogenate [38]. Again there was clear evidence of inter-linking of bacteria by these structures (Fig. 9a, c, e and f).

In three experiments in this work, non-cell-associated organisms in the supernates of RIIAs were examined by SEM, as had been done in the Caco- 2 cell system, to determine the effect of gut-conditioning followed by exposure to gut tissue in the RIIA. Again, it was striking that continued physical contact with epithelial cells was not essential for appendage formation, neither was gut-conditioning (Fig. 9c). S. Typhimurium TML produced many appendages under all conditions (data not shown). For LT7(pHC20.2) the extent of production of appendages was less than for TML, but more appendages were seen when gut tissue was present in the RIIA chambers (Fig. 9c and d) than when it was absent (Fig. 9e). LT7(pHC20.2) organisms which had 


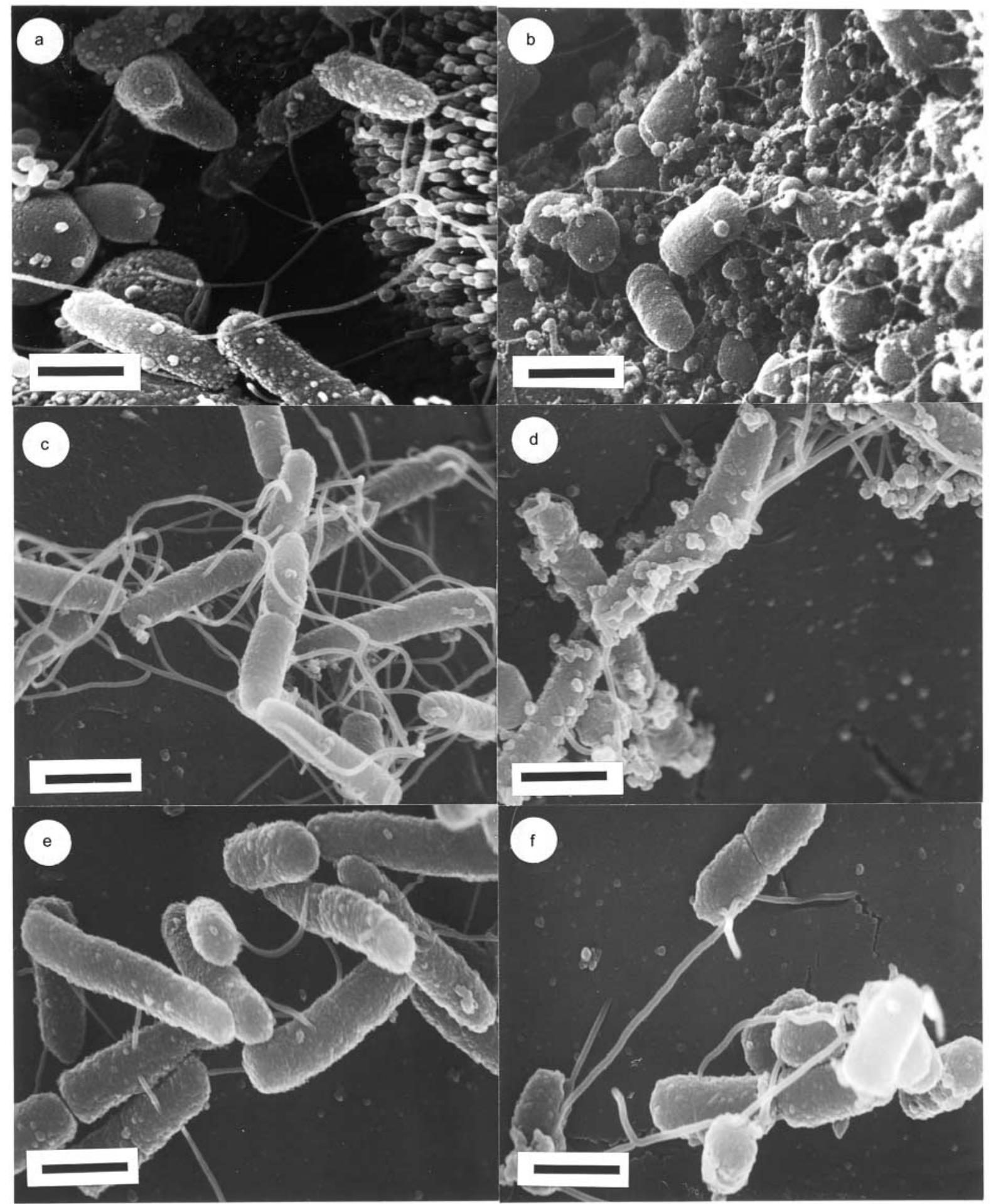

Fig. 9. SEM analysis of LT7(pHC20.2) and LT7 (pHC79) in the RIIA. a, b: enterocyte-associated bacteria (a) by $2 \mathrm{~h}$, LT7(pHC20.2) showed appendage formation irrespective of gut-conditioning. However, (b) it was much easier to find fields of organisms entering enterocytes if the organisms had been gut-conditioned. Bacterial cells penetrating the microvillous cells were smooth, having shed appendages which were seen in abundance in the vicinity. $\mathbf{c}-\mathbf{f}$ : bacteria sampled from the chamber fluid at 30 min. (c) LT7(pHC20 2) grown without gut-conditioning but with gut tissue in the chamber; (d) gut-conditioned LT7(pHC20·2) with gut in the chamber, note field shows surface blebbing; (e) gut-conditioned LT7(pHC20.2) with no gut in the chamber; (f) gutconditioned LT7(pHC79) with gut in the chamber. Bars represent $0.5 \mu \mathrm{m}$.

been gut-conditioned and then exposed to gut tissue showed an additional feature of surface blebbing (Fig. 9d). LT7(pHC79) also expressed appendages (Fig. 9f) but the extent of production of appendages was less than for $\mathrm{LT} 7(\mathrm{pHC} 20 \cdot 2)$.
Sequence of $\mathrm{pHC} 20 \cdot 2$ and location on the $S$. Typhimurium chromosome

Southern blotting experiments showed no homology between $\mathrm{pHC} 20 \cdot 2$ and a member of the TML library carrying the inv/spa region, which is part of SPI-1 
located at centisome 63 on the $S$. Typhimurium genetic map. Pulsed-field gel electrophoresis of $B \ln \mathrm{I}$ and $X b a \mathrm{I}$ restriction digests of genomic DNA of $S$. Typhimurium strain TML, and subsequent probing with $\mathrm{pHC} 20 \cdot 2$, located $\mathrm{pHC} 20 \cdot 2$ to the $790-\mathrm{kb} B \ln \mathrm{I}$ fragment, and the $800-\mathrm{kb} X b a \mathrm{I}$ fragment [39], positioning pHC20.2 between centisomes 23.9 and 29.7 on the $S$. Typhimurium genetic map. An unannotated draft of the sequence of $S$. Typhimurium strain LT2 is now available [40]. A BLAST search with sequences from each end of pHC20.2 match a single contig and delimit a 35.4-kb region. Sequences from random deletion derivatives of pHC20. 2 are located between these two extremes. It is possible to deduce from the sequence data that pHC20.2 encodes: the hpa operon which encodes the 4-hydroxyphenylacetate catabolic pathway that is found in E. coli W [41] and $S$. Dublin (accession no. AF144422), a region involved in tolerance to copper scs [42], the Typhimurium agp gene [42], the put operon involved in proline utilisation [43], a protein $\mathrm{PhoH}$ which is induced by phosphate starvation in E. coli [44] and WrbA a stationary phase trp repressor binding protein [45]. There are at least 10 other open reading frames whose functions have not been assigned. The put operon is located at centisome 25 on the $S$. Typhimurium genetic map confirming the location of $\mathrm{pHC} 20 \cdot 2$. The clone $\mathrm{pHC} 20 \cdot 2$ also encodes part of regulatory protein CopR which is found in Pseudomonas syringae [46] and E. coli [47] and $S$. Dublin [4]. CopR is located adjacent to SPI-5 between 17 and 21.5 centisomes on the $S$. Dublin chromosome [4]. Therefore, the clone $\mathrm{pHC} 20 \cdot 2$ is located c. $1.7 \mathrm{~kb}$ upstream of SPI-5.

\section{Detection of pHC20.2 in the S. Typhimurium LT7 genome}

A DIG-labelled $\mathrm{pHC} 20 \cdot 2$ probe hybridised to common fragments in restriction endonuclease digests of $S$. Typhimurium strains TML and LT7 genomic DNA, indicating that $\mathrm{pHC} 20.2$ is present in strain LT7; however, these sequences may not be fully functional.

\section{Discussion}

This work describes the isolation of LT7(pHC20.2), a clone derived from the invasive strain of $S$. serotype Typhimurium (TML) and isolated by iterative passes through the RIIA. Limited genetic analyses indicate that $\mathrm{pHC} 20.2$ is distinct from those SPIs known to date; it maps at $c$. centisome 25 on the salmonella chromosome close to, but distinct from, SPI-5 and does not contain the inv/spa region of SPI-1. Also, strain LT7 contains sequences recognised by probes which detect LT7(pHC20.2), suggesting that in strain LT7 they are not fully functional.

Taken as a whole, the data point to the existence of hitherto unreported gut tissue-/Caco-2 cell-modulated properties of $S$. Typhimurium of potential significance in the gastro-enteritic virulence of this pathogen. In this work, attention was largely focused on the biological properties of LT7(pHC20.2), in particular the effect of gut tissue and gut-derived Caco-2 cells on LT7 $(\mathrm{pHC} 20 \cdot 2)$ phenotypes.

Gut-induced changes in the profile patterns of various OMPs were demonstrated in $S$. Typhimurium strains TML, LT7, LT7(pHC20.2) and LT7(pHC79). Gutconditioning suppressed the expression of a triplet of OMPs (putatively OmpF, OmpC and PhoE) and a 49.5$\mathrm{kDa}$ OMP, and induced expression of a $47-\mathrm{kDa}$ OMP. These changes are construed as bacterial adaptations to a gut-enriched in-vitro environment but are unlikely to be involved per se in the invasion process, as they occurred in the hypo-invasive as well as the invasive strains. One can speculate that decreased amounts of these porins is a stratagem to make the bacteria less susceptible to injurious gut constituents. The growthenhancing effect of both gut tissue and Caco-2 cells resulted in restoration of $\mathrm{LT} 7(\mathrm{pHC} 20 \cdot 2)$ growth characteristics to levels similar to those observed in LT7(pHC79). It is highly likely that this phenotype was partly responsible for the successful isolation of pHC20.2; however, it could have more fundamental significance. This ability to continue to grow in a 'gutenvironment' during which co-ordinate expression of other potential virulence attributes occurred could confer a colonisation advantage over other competing organisms which either were not stimulated to grow, or could grow but not co-ordinately express additional relevant virulence attributes.

Increased levels of flagellin were observed after gutconditioning of LT7(pHC20.2) but not LT7(pHC79) and these levels were further increased on exposure of LT7(pHC20.2) to Caco-2 cells. The increased amount of flagellin may reflect longer rather than more flagella, but as flagella are very sensitive to shearing, the lengths of flagella are difficult to ascertain by transmission electron microscopy (TEM). Moreover, quantitative analyses by TEM are inherently difficult to achieve because of the enormous numbers of organisms that must be examined to provide a statistically significant sample. Moreover it was not possible to demonstrate a correlation between increased production of flagellin with increases in motility as observed in 'sloppy agar' tests (data not shown). Therefore, it is difficult to interpret the significance of the changes in flagellin production. Virulent salmonellae may become more motile in vivo, thereby achieving a greater number of productive cell attachments and subsequent invasion events mediated by non-flagellar adhesins. Alternatively, flagella themselves could bear a primary adhesin and any increase in their expression would make flagella-mediated attachment more effective. The data from the present study cannot discriminate between these possibilities. In general, the role of flagella as mediators of attachment and invasion has never been 
satisfactorily resolved (see [48-50]). A more recent suggestion regarding the role of flagellin stems from a study of the interaction of $S$. Typhimurium and model intestinal epithelia derived from monolayers of T84 or HT29-Cl.19A cells [51]. S. Typhimurium translocated flagellin across such epithelia stimulating the secretion of interleukin (IL)-8, a potent mediator of the inflammatory response. Earlier quantitative work in vivo with invasive $S$. Typhimurium strains (including TML) correlated gastro-enteritic virulence with the ability to induce a massive intra-luminal influx of polymorphonuclear cells (PMNs) [52]. The full expression of gastroenteritic virulence may require gutstimulated increase in flagellin production which in turn gives rise to the induction of the massive influx of PMNs (so characteristic of gut infection with $S$. Typhimurium) which in turn could destabilise gut epithelia further aiding invasion of gut mucosa by salmonellae.

Appendages emanating from bacteria and attaching to microvilli could be the mediators of attachment or the means of delivery of the actual invasins (or both). Several animal and plant pathogens have been shown to express type III secretion systems that are involved in the secretion of virulence factors; in some cases these are translocated directly from the bacteria into the target cell $[3,5,53,54]$. The SPI-1-encoded type III secretion system in $S$. Typhimurium $[55,56]$ and $S$. Dublin $[57,58]$ has been shown to be capable of translocation of effector proteins into the cytosol of cultured cells. Many of the genes encoding these type III secretion systems have close homologues in the flagella assembly genes. In at least two cases (the EspA filaments of EPEC and EHEC [59] and the IpaB and IpaC proteins of Shigella [60]) the proteins secreted by these systems form filamentous structures. In EPEC and EHEC it has been demonstrated that the filaments function as a 'molecular syringe', translocating effector molecules directly into the eukaryotic cell. Filamentous appendages have also been described for $S$. Typhimurium that were originally thought to be SPI-1 encoded [61]; however, recent data contradict this assertion [62].

The appendages expressed by LT7(pHC20-2) (Figs. 7 and 9) have several features in common with those described previously $[38,61,62]$ : their dimensions $(60-70 \mathrm{~nm})$ are similar, they attach to target cells and they inter-link bacteria. Sequence analysis (alluded to above) makes it unlikely that $\mathrm{pHC} 20 \cdot 2$ encodes the appendages seen here and does not encode the inv-spa region; however, it may encode a regulator of these genes. The sequences encoded within pHC20.2 also increase the invasiveness of strain LT7 and mediate other phenotypic changes, such as expression of flagellin and, perhaps, motility, in response to gutderived factors. The expression and functioning of flagellar components is controlled by a variety of genes, which are located at more than one position on the chromosome [63]. As the chromosomal location of sequences encoded within pHC20.2 is different from the chromosomal locations of the genes known to be involved in flagella, invasin and porin expression, it is likely that pHC20.2 encodes a pleiotropic regulator of genes implicated in adaptation to a gut environment and gastro-enteritic virulence. This scenario has a partial functional resonance with the recent description [64] of the co-regulation in $S$. Typhi of expression of flagellar genes and genes encoded by SPI-1 involved in invasion of Henle-407 cells, by the Flagellar master regulator (flhD) or Flagellar sigma factor (fliA). However, this type of co-regulation was much less marked in $S$. Typhimurium [64]. Importantly, the regulatory system described in the present work relates to $S$. Typhimurium, is encoded on a different locus, is demonstrably 'gut-inducible', and concerns invasion of enterocytes in situ or in gut-derived Caco-2 cells. Another regulator, Salmonella $\mathrm{SsrB}$, has been described recently that activates a global regulon of horizontally acquired genes [65]. SsrB is encoded within SPI-2 but has now been shown to activate genes outside SPI-2. However, it is extremely unlikely that $\mathrm{SsrB}$ is related to that described in the present work as $\mathrm{pHC} 20 \cdot 2$ affects $S$. Typhimurium extracellularly, whereas $\mathrm{SsrB}$ is maximally operative within cells [65].

It has been suggested that contact with or exposure to the host cell surface is a prerequisite for appendage formation [61], although short appendages have been observed on bacteria attached to cell culture supports [62]. It has been demonstrated clearly here that appendage formation occurred in organisms obtained from Caco-2 cell and RIIA supernates, which suggests that constant contact with cells is not an absolute requirement for expression of appendages. Gut-conditioning enhanced the formation of appendages during infection of Caco-2 cells, whereas in the RIIA experiments appendages were observed without gutconditioning, although pre-treated organisms were observed invading more frequently. The simplest explanation that ties these facts together is that there is a 'gut factor' which stimulates the formation of appendages, and the co-ordinate expression of invasins. This factor would be present when the organisms are pre-grown in the presence of gut homogenate where it has the effect of priming them to produce appendages and invasins; it would also be present in the RIIA. It seems probable that the activity of this inducer is both time and concentration dependent. In the RIIA, LT7(pHC20.2), even without gut-conditioning, may be exposed to the appendage-inducing stimulus for sufficiently long or at sufficient concentration for appendage expression to be evident. However, there may not be sufficient exposure for subsequent full expression of the invasins. Gut-conditioning may poise LT7(pHC20.2) for more rapid expression of these appendages during a RIIA - as a result of the continued stimulus provided by the fresh tissue - thus allowing time for the expression of invasins. It must be remembered that the organ culture system can be used 
only in short-term experiments, a restriction that does not apply to infection in vivo. The factor released by gut tissue may not comprise a single component. The phenomenology suggests that a similar factor could be released by Caco- 2 cells, which are gut-derived cells, possibly in lower concentrations or in an incomplete form. However, it is recognised that the Caco-2 cell factor may be structurally different though functionally similar.

LT7(pHC20.2) grown in the absence of gut homogenate displayed appendages at $2 \mathrm{~h}$ after challenge but were relatively non-invasive for rabbit ileal explants. Others have shown that some mutants that were defective in invasion of Caco-2 and MDCK monolayers were able to express wild-type appendages [62]. Hence, while appendage expression would appear to play a role in invasion, appendage formation per se does not confer invasiveness.

It is intriguing to speculate as to the possible significance of the inter-linking of bacteria by appendages (Figs. 7 and 9). This could be an adventitious phenomenon reflecting the nature of structures embedded in the bacterial cell wall and the ability of these structures to interact with appendages from other bacteria. Another equally speculative suggestion is that appendages are structures for communication between bacteria. This is an emerging theme in bacterial physiology and constitutes a way in which organisms can act in a 'multicellular' fashion to prepare for ensuing assaults on the host. Appendage 'networks' may also constitute a way of increasing the local concentration of bacteria or allow neighbouring organisms to communicate to switch on their invasion genes as a co-ordinated group in response to environmental stimuli. However, while this could be true for $S$. Typhimurium [38] and $S$. Dublin [16] which are frequently observed invading in groups or 'microcolonies', it is less likely to be true for $S$. Choleraesuis which is most frequently observed invading as single cells [16].

The presence of $\mathrm{pHC} 20 \cdot 2$ in strain LT7 did not increase invasion or appendage formation of $S$. Typhimurium LT7 to the levels seen in strain TML. Moreover, these phenomena appeared not to be gut-inducible in $S$. Typhimurium TML. The absolute levels of invasion achieved with LT7(pHC20.2), were in general greater than LT7(pHC79) and less than $S$. Typhimurium TML. Although, in the experiments reported here, invasiveness of $S$. Typhimurium TML was not overtly enhanced by gut-conditioning, the possible existence of an inducible invasion pathway in wild-type $S$. Typhimurium TML is not without some foundation. It has been shown previously that the invasiveness of $S$. Typhimurium TML is determined not only by the gut tissue used in a given RIIA (a reflection of inter-animal variation) but also by the nature of the medium in which the organism is grown. Differences in the invasiveness of strain TML were demonstrated when different complex media and different batches of ostensibly the same complex medium were used [13]. Similar observations were made in earlier work with respect to the culture medium and also the batch of calf serum used in maintaining HEp-2 cells [66]. Against such a background one would have to postulate that by removing the genes encoded on $\mathrm{pHC} 20 \cdot 2$ from their normal 'genetic environment' or by cloning them in multiple copies, normal regulation is altered.

The differences between strains TML and LT7 (pHC20.2) could reflect their relative efficiencies of response to gut induction. Strain TML may require a lower critical level of inducer than LT7(pHC20.2). Strain TML could contain alleles which make the gutinducible pathway function more effectively. This would reduce the critical level of, and time of exposure to the inducer required for full invasiveness, thus obviating the apparent need for gut-conditioning: sufficient quantities of the inducer may be present during an invasion assay. In the investigations reported here only partial induction of LT7(pHC20.2) may have been achieved as measured against the TML standard. Media were supplemented with the pelleted fraction of gut homogenates. Growth regimens were determined empirically as conditions were sought that emulated as closely as possible those encountered during the passage experiment which gave rise to the isolation of $S$. Typhimurium LT7(pHC20.2) in the first instance. It is possible that further induction may be achieved by utilising different fractions of the gut homogenate or by introducing the inducing factor(s) at different stages, for different times under different conditions of growth in vitro.

However, there is a different kind of explanation for the differential invasiveness of LT7(pHC20.2) and TML. Just as for cultured cells [67] there could be numerous pathways available to facilitate bacterial invasion of epithelial cells in situ. The presence of pHC20.2 may complement $S$. Typhimurium LT7 for one such pathway involved in invasion that does not by itself elicit TMLlike levels of invasiveness. The pathway that results in eliciting high levels of TML-like invasiveness may be a constitutive one which is absent or non-functional in strain LT7, whereas the one cloned into LT7(pHC20 2) is gut-inducible.

This work was supported by a grant from the Wellcome Trust (no. 046719 to M.R. and J.M.L.) and the BBSRC (A.J.B.) and MRC G.4600017 grant for bioinformatics infrastructure. We are grateful to Karin Sweryda for expert technical assistance.

\section{References}

1. Galán JE, Curtiss R. Cloning and molecular characterization of genes whose products allow Salmonella typhimurium to penetrate tissue culture cells. Proc Natl Acad Sci USA 1989; 86: $6383-6387$.

2. Hacker J, Blum-Oehler G, Mühldorfer I, Tschäpe H. Path- 
ogenicity islands of virulent bacteria: structure, function and impact on microbial evolution. Mol Microbiol 1997; 23: 10891097.

3. Groisman EA, Blanc-Potard A-B, Uchiya K. Pathogenicity islands and the evolution of Salmonella virulence. In: Kaper JB, Hacker J (eds) Pathogenicity islands and other mobile genetic elements. Washington, DC, American Society for Microbiology. 1999: 127-150.

4. Wood MW, Jones MA, Watson PR, Hedges S, Wallis TS, Galyov EE. Identification of a pathogenicity island for Salmonella enteropathogenicity. Mol Microbiol 1998; 29: 883-891.

5. Wallis TS, Galyov EE. Molecular basis of Salmonella-induced enteritis. Mol Microbiol 2000; 36: 997-1005.

6. Lucas RL, Lee CA. Unravelling the mysteries of virulence gene regulation in Salmonella typhimurium. Mol Microbiol 2000; 36: 1024-1033.

7. Cooper GL, Venables LM, Woodward MJ, Hormaeche CE Invasiveness and persistence of Salmonella enteritidis, Salmonella typhimurium, and a genetically defined $S$. enteritidis aro $A$ strain in young chickens. Infect Immun 1994; 62: 4739-4746.

8. Frost AJ, Bland AP, Wallis TS. The early dynamic response of the calf ileal epithelium to Salmonella typhimurium. Vet Pathol 1997; 34: 369-386.

9. Bolton AJ, Osborne MP, Wallis TS, Stephen J. Interaction of Salmonella choleraesuis, Salmonella dublin and Salmonella typhimurium with porcine and bovine terminal ileum in vivo. Microbiology 1999; 145: 2431-2441.

10. Giannella RA, Formal SB, Dammin GJ, Collins H. Pathogenesis of Salmonellosis: studies of fluid secretion, mucosa invasion, and morphologic reaction in the rabbit ileum. $J$ Clin Invest 1973; 52: 441-453.

11. Stephen J, Wallis TS, Starkey WG, Candy DCA, Osborne MP, Haddon S. Salmonellosis: in retrospect and prospect. In: Microbial toxins and diarrhoeal disease. Ciba Foundation Symposium no. 112. London, Pitman. 1985: 175-192.

12. Stephen J, Amin II, Douce GR. Experimental Salmonella typhimurium-induced gastroenteritis. In: Cabello F, Hormaeche C, Mastroeni P, Bonina L (eds) Biology of Salmonella (NATOASI Series A, vol 245). New York, Plenum Press. 1993: 199-209.

13. Amin II, Douce GR, Osborne MP, Stephen J. Quantitative studies of invasion of rabbit ileal mucosa by Salmonella typhimurium strains which differ in virulence in a model of gastroenteritis. Infect Immun 1994; 62: 569-578.

14. de Kort G, Bolton A, Martin G, Stephen J, van de Klundert JAM. Invasion of rabbit ileal tissue by Enterobacter cloacae varies with the concentration of OmpX in the outer membrane. Infect Immun 1994; 62: 4722-4726.

15. Lodge J, Douce GR, Amin I et al. Biological and genetic characterization of $\operatorname{Tn} p h o A$ mutants of Salmonella typhimurium TML in the context of gastroenteritis. Infect Immun 1995; 63: $762-769$

16. Bolton AJ, Martin GD, Osborne MP, Wallis TS, Stephen J. Invasiveness of Salmonella serotypes Typhimurium, Choleraesuis and Dublin for rabbit terminal ileum in vitro. $J$ Med Microbiol 1999; 48: 801-810.

17. Lodge JM, Bolton AJ, Martin GD, Osborne MP, Ketley JM, Stephen J. A histotoxin produced by Salmonella. J Med Microbiol 1999; 48: 811-818.

18. Lilleengen K. Typing of Salmonella typhimurium by means of bacteriophage: experimental bacteriologic study for the purpose of devising phage-typing method to be used as an aid in epidemiologic and epizootologic investigations in outbreaks of typhi-murium infection. Acta Pathol Microbiol Scand 1948; S77: $11-125$

19. Vazquez-Torres A, Jones-Carson J, Bäumler AJ et al. Extraintestinal dissemination of Salmonella by CD18-expressing phagocytes. Nature 1999; 401: 804-808

20. Lodge JM, Robey M, Stephen J, Brown NL. Iterative selection from a Salmonella typhimurium cosmid library can lead to the isolation of an atypically small plasmid. FEMS Microbiol Lett 1999; 170: 355-361.

21. Wallis TS, Starkey WG, Stephen J, Haddon SJ, Osborne MP, Candy DCA. The nature and role of mucosal damage in relation to Salmonella typhimurium-induced fluid secretion in the rabbit ileum. J Med Microbiol 1986; 22: 39-49.

22. Martin GD, Chart $\mathrm{H}$, Threlfall EJ et al. Invasiveness of Salmonella serotypes Typhimurium and Enteritidis of human gastro-enteritic origin for rabbit ileum: role of LPS, plasmids and host factors. J Med Microbiol 2000; 49: 1011-1021.

23. Hohn B, Collins J. A small cosmid for efficient cloning of large DNA fragments. Gene 1980; 11: 291-298.

24. Miller IA, Chatfield S, Dougan G, Desilva L, Joysey HS, Hormaeche C. Bacteriophage P22 as a vehicle for transducing cosmid gene banks between smooth strains of Salmonella typhimurium: use in identifying a role for $\operatorname{aroD}$ in attenuating virulent Salmonella strains. Mol Gen Genet 1989; 215: 312-316.

25. Clarke L, Carbon J. A colony bank containing synthetic Col E1 hybrid plasmids representative of the entire E. coli genome. Cell 1976; 9: 91-99.

26. Sambrook J, Fritsch EF, Maniatis T. Molecular cloning: a laboratory manual, 2nd edn. Cold Spring Harbor, New York, Cold Spring Harbor Press. 1989.

27. Bolton AJ, Osborne MP, Stephen J. Comparative study of the invasiveness of Salmonella serotypes Typhimurium, Choleraesuis and Dublin for Caco-2 cells, HEp-2 cells and rabbit ileal epithelia. J Med Microbiol 2000; 49: 503-511.

28. Laemmli UK. Cleavage of structural proteins during the assembly of the head of bacteriophage T4. Nature 1970; 227: $680-685$.

29. Osborn MJ, Gander JE, Parisi E, Carson J. Mechanism of assembly of the outer membrane of Salmonella typhimurium. Isolation and characterization of cytoplasmic and outer membrane. J Biol Chem 1972; 247: 3962-3972.

30. Sauerbaum S, Geis G, Josenhans C, Opferkuch W. Biochemical studies of Helicobacter mustelae fatty acid composition and flagella. Infect Immun 1992; 60: 1695-1698.

31. Devereux J, Haeberli P, Smithies O. A comprehensive set of sequence analysis programs for the VAX. Nucleic Acids Res 1984; 12: 387-395.

32. Pearson WR, Lipman DJ. Improved tools for biological sequence comparison. Proc Natl Acad Sci USA 1988; 85: 2444-2448.

33. Chomczynski P. One-hour downward alkaline capillary transfer for blotting of DNA and RNA. Anal Biochem 1992; 201: $134-139$.

34. Feinberg AP, Vogelstein B. A technique for radiolabeling DNA restriction endonuclease fragments to high specific activity. Anal Biochem 1983; 132: 6-13.

35. Southern EM. Detection of specific sequences among DNA fragments separated by gel electrophoresis. J Mol Biol 1975; 98: $503-517$.

36. Okazaki N, Matsuo S, Saito K, Tominaga A, Enomoto M. Conversion of the Salmonella phase 1 flagellin gene $f i C$ to the phase 2 gene $f j B$ on the Escherichia coli K-12 chromosome. J Bacteriol 1993; 175: 758-766.

37. Kondoh K, Hotani H. Flagellin from Escherichia coli K12: polymerization and molecular weight in comparison with Salmonella flagellins. Biochim Biophys Acta 1974; 336: 117-139.

38. Worton KJ, Candy DCA, Wallis TS et al. Studies on early association of Salmonella typhimurium with intestinal mucosa in vivo and in vitro: relationship to virulence. J Med Microbiol 1989; 29: 283-294.

39. Liu S-L, Hessel A, Sanderson KE. The XbaI-Bln I-Ceu I genomic cleavage map of Salmonella typhimurium LT2 determined by double digestion, end labelling, and pulsed-field gel electrophoresis. J Bacteriol 1993; 175: 4104-4120.

40. http://genome.wustl.edu/gsc/bacterial/salmonella.shtml.

41. Prieto MA, Díaz E, García JL. Molecular characterization of the 4-hydroxyphenylacetate catabolic pathway of Escherichia coli W: engineering a mobile aromatic degradative cluster. $J$ Bacteriol 1996; 178: 111-120.

42. Gupta SD, Wu HC, Rick PD. A Salmonella typhimurium genetic locus which confers copper tolerance on coppersensitive mutants of Escherichia coli. J Bacteriol 1997; 179: 4977-4984.

43. Hahn DR, Myers RS, Kent CR, Maloy SR. Regulation of proline utilization in Salmonella typhimurium: molecular characterization of the put operon, and DNA sequence of the put control region. Mol Gen Genet 1988; 213: 125-133.

44. Kim S-K, Makino K, Amemura M, Shinagawa H, Nakata A. Molecular analysis of the phoH gene, belonging to the phosphate regulon in Escherichia coli. J Bacteriol 1993; 175: $1316-1324$

45. Yang WP, Ni L, Somerville RL. A stationary-phase protein of 
Escherichia coli that affects the mode of association between the trp repressor protein and operator-bearing DNA. Proc Natl Acad Sci USA 1993; 90: 5796-5800.

46. Mills SD, Jasalavich CA, Cooksey DA. A two-component regulatory system required for copper-inducible expression of the copper resistance operon of Pseudomonas syringae. $J$ Bacteriol 1993; 175: 1656-1664.

47. Itoh $\mathrm{T}$, Aiba $\mathrm{H}$, Baba $\mathrm{T}$ et al. A 460-kb DNA sequence of the Escherichia coli $\mathrm{K}-12$ genome corresponding to the 40.1-50.0 min region on the linkage map. DNA Res 1996; 3: 379-392.

48. Lockman HA, Curtiss R. Virulence of non-type 1-fimbriated and nonfimbriated nonflagellated Salmonella typhimurium mutants in murine typhoid fever. Infect Immun 1992; 60: 491-496.

49. Lockman HA, Curtiss R. Salmonella typhimurium mutants lacking flagella or motility remain virulent in $\mathrm{BALB} / \mathrm{c}$ mice. Infect Immun 1990; 58: 137-143.

50. Allen-Vercoe E, Woodward MJ. The role of flagella, but not fimbriae, in the adherence of Salmonella enterica serotype Enteritidis to chick gut explant. J Med Microbiol 1999; 48: 771-780.

51. Gerwitz AT, Simon PO, Schmit CK et al. Salmonella typhimurium translocates flagellin across intestinal epithelia, inducing a proinflammatory response. J Clin Invest 2001; 107: $99-109$.

52. Wallis TS, Hawker RJH, Candy DCA et al. Quantification of the leucocyte influx into rabbit ileal loops induced by strains of Salmonella typhimurium of different virulence. $J$ Med Microbiol 1989; 30: 149-156.

53. Darwin KH, Miller VL. Molecular basis of the interaction of Salmonella with the intestinal mucosa. Clin Microbiol Rev 1999; 12: 405-428.

54. Hueck CJ. Type III protein secretion systems in bacterial pathogens of animals and plants. Microbiol Mol Biol Rev 1998; 62: 379-433

55. Fu Y, Galán JE. The Salmonella typhimurium tyrosine phosphatase SptP is translocated into host cells and disrupts the actin cytoskeleton. Mol Microbiol 1998; 27: 359-368.

56. Collazo CM, Galán JE. The invasion-associated type III system of Salmonella typhimurium directs the translocation of Sip proteins into the host cell. Mol Microbiol 1997; 24: 747-756.
57. Galyov EE, Wood MW, Rosqvist R et al. A secreted effector protein of Salmonella dublin is translocated into eukaryotic cells and mediates inflammation and fluid secretion in infected ileal mucosa. Mol Microbiol 1997; 25: 903-912.

58. Wood MW, Rosqvist R, Mullan PB, Edwards MH, Galyov EE. SopE, a secreted protein of Salmonella dublin, is translocated into the target eukaryotic cell via a sip-dependent mechanism and promotes bacterial entry. Mol Microbiol 1996; 22: 327-338.

59. Frankel G, Phillips AD, Rosenshine I, Dougan G, Kaper JB, Knutton S. Enteropathogenic and enterohaemorrhagic Escherichia coli: more subversive elements. Mol Microbiol 1998; 30: 911-921.

60. Parsot C, Ménard R, Gounon P, Sansonetti PJ. Enhanced secretion through the Shigella flexneri Mxi-Spa translocon leads to assembly of extracellular proteins into macromolecular structures. Mol Microbiol 1995; 16: 291-300.

61. Ginocchio CC, Olmsted SB, Wells CL, Galán JE. Contact with epithelial cells induces the formation of surface appendages on Salmonella typhimurium. Cell 1994; 76: 717-724.

62. Reed KA, Clark MA, Booth TA et al. Cell-contact-stimulated formation of filamentous appendages by Salmonella typhimurium does not depend on the type III secretion system encoded by Salmonella pathogenicity island 1. Infect Immun 1998; 66: 2007-2017.

63. Sanderson KE, Hessel A, Rudd KE. Genetic map of Salmonella typhimurium, edition VIII. Microbiol Rev 1995; 59: $241-303$.

64. Eichelberg K, Galán JE. The flagellar sigma factor FliA $\left(\sigma^{28}\right)$ regulates the expression of Salmonella genes associated with the centisome 63 type III secretion system. Infect Immun 2000; 68: $2735-2743$

65. Worley MJ, Ching KHL, Heffron F. Salmonella SsrB activates a global regulon of horizontally acquired genes. Mol Microbiol 2000; 36: 749-761.

66. Douce GR, Amin II, Stephen J. Invasion of HEp-2 cells by strains of Salmonella typhimurium of different virulence in relation to gastroenteritis. J Med Microbiol 1991; 35: 349-357.

67. Stone BJ, Garcia CM, Badger JL, Hassett T, Smith RIF, Miller VL. Identification of novel loci affecting entry of Salmonella enteritidis into eukaryotic cells. J Bacteriol 1992; 174: 3945-3952. 